\title{
Influence of Water Inrush from Excavation Surface on the Stress and Deformation of Tunnel-Forming Structure at the Launching-Arrival Stage of Subway Shield
}

\author{
Shusheng Lv, ${ }^{1}$ Wen Liu $\mathbb{D}^{1,2}$ Shihong Zhai, ${ }^{3,4}$ and Peishuai Chen $\mathbb{D}^{5}$ \\ ${ }^{1}$ CCCC Second Harbor Engineering Co., Ltd., No. 11 Jinyin Lake Road, Dongxihu District, Wuhan 430074, China \\ ${ }^{2}$ School of Civil Engineering \& Mechanics, Huazhong University of Science and Technology, Wuhan, Hubei 430074, China \\ ${ }^{3}$ Key Laboratory of Large-Span Bridge Construction Technology for Transportation Industry, No. 11 Jinyin Lake Road, \\ Dongxihu District, Wuhan 430074, China \\ ${ }^{4}$ Research and Development Center of Transportation Industry of Intelligent Manufacturing Technologies of Transport \\ Infrastructure, No. 11 Jinyin Lake Road, Dongxihu District, Wuhan 430074, China \\ ${ }^{5}$ CCCC Highway Bridges National Engineering Research Centre Co., Ltd., No. 11 Jinyin Lake Road, Dongxihu District, \\ Wuhan 430074, China \\ Correspondence should be addressed to Wen Liu; 379047775@qq.com
}

Received 13 May 2019; Revised 26 August 2019; Accepted 5 September 2019; Published 30 October 2019

Academic Editor: Abdul Aziz bin Abdul Samad

Copyright ( $) 2019$ Shusheng Lv et al. This is an open access article distributed under the Creative Commons Attribution License, which permits unrestricted use, distribution, and reproduction in any medium, provided the original work is properly cited.

\begin{abstract}
The launching-arrival stage of the shield is the most dangerous construction stage in subway construction. During the conversion process of the soil and air medium in the shield machine, water inrush at the excavation surface often occurs because of the effect of groundwater. Previous research has focused on the overall stress and deformation of existing tunnels caused by water inrush from the excavation face of the shield machine excavation stage. However, the stress and deformation states of the segments and anchors at different assembly locations of the tunnel, as well as the interaction between the soil reinforcement region and the segments and anchors in the launching-arrival stage have not been considered in previous studies. In this study, the inrush model of the launching-arrival stage of the subway shield was established by utilizing the equivalent refinement modeling technology and ABAQUS simulation analysis with consideration of the fluid-solid coupling effect of water and soil to study the influences of different water head differences on the mechanical and deformation properties of segments and anchors in shield construction under the conditions of water inrush on the excavation surface. The results showed that the water inflow from the tunnel excavation surface caused significant surface subsidence at the tunnel portal, vertical convergence at the cross section of the shield tunnel, and significant increases in the axial and shear forces on the bolt. In addition, based on the existing subway regulation, combined with the simulation results of soil reinforcement measures at different depths, the emergency control criterion for controlling water inrush on the excavation surface was established by using the depth of soil reinforcement. The minimum depth of the reinforced soil from the ground surface at $15 \mathrm{~m}$ is recommended to ensure construction safety of the subway shield at the launching-arrival stage.
\end{abstract}

\section{Introduction}

Since China's first subway shield tunnel was put into operation in the 1990s, metro tunnels have played a critical role in improving urban infrastructure systems and promoting public transport in China $[1,2]$. Compared with the upper structure, the shield tunnel, as a type of underground structure, has various drawbacks, such as uncertainty, irreversibility, high construction and accident costs, and long construction period. In particular, shield construction at the launching-arrival stage has the highest risk. When the shield machine excavates in the upper-soft lower-hard stratum 
with rich groundwater, it might cause water inrush disasters of different degrees, resulting in subsidence and deformation of the ground, as well as changes in the stress and formation state of the shield tunnel, which significantly affect the service performance of subway tunnels [3, 4]. Lee and Ishihara reported that a section of a tunnel in Kaohsiung collapsed owing to uncontrolled leakage of groundwater that spurted from the bottom of the shield tunnel machine face as a result of piping or hydraulic fracturing [5]. Similarly, Li reported a sudden water inrush disaster in the construction site of the Ludao Lake-Huyong shield section of Foshan Metro Line 2 in Nanzhuang, Chancheng, Foshan City, Guangdong Province, causing severe deformation and damage of the tunnel segment, as well as collapse of more than 30 meters of the ground [6].

To prevent economic losses and casualties caused by water inrush accidents in tunnel shield construction, the disaster risk of and control measures for water inrush accidents in tunnels have been studied in China and other countries from the perspective of engineering practice and numerical simulation. Taking the Dou-Mo highway rock tunnel from Shanghai to Kunming of China as an example, Shi et al. numerically simulated the water inrush condition of the tunnel in the deep water-rich area and evaluated the influence of construction parameters on various curtain grouting sections based on the numerical analysis results [7]. Considering a coal rock tunnel in an enriched aquifer that might cause water flooding and sand gushing in the working face, Yang et al. designed a test model for the mixed water and sand inrush and transferred to simulate the startup, transfer, and inrush process in the overburden fracture channel [8]. Taking the water inrush accident in the Dadushan rock tunnel located in the southwestern karst region of Guizhou Province, China, as an example, Qin et al. conducted a comprehensive study on the TMRS by utilizing forward modeling and numerical experiments, in which the relationship between the magnetic resonance signal response and the position and water content of water-bearing structures was identified by forward modeling [9]. In a case study of water inrush and mud gushing railway rock tunnels, Zhou and Liao analyzed the mechanism of water inrush and mud gushing under high water pressure and put forward appropriate treatment methods. According to numerous studies on water inrush disasters, the water inrush and mud gushing in broken rock tunnels can be classified into two main types, namely, partial cracking in the cross section, and longitudinal water inrush and landslide [10]. Although various studies have been extensively conducted, the main objects are rock tunnel of the railway and highway, and there are few studies on the sudden water inrush condition of the urban subway shield tunnel.

At present, the only study of water inrush in subway shield construction is mainly focused on the tunneling process of shield tunneling. Ye and Liu investigated the influence of large water inflow from the excavation face on segmental lining damage when the earth-pressure balance (EPB) method was used in shield tunneling in a saturated silty sand layer [11]. After studying the water inrush in the tunnel construction of the subway tunnel in loess strata under the influence of water environment, Qiu et al. found that the water pressure positively correlated with the surface subsidence during the process of water inrush [12]. In other words, the closer to the water source, the greater surface subsidence is. In the study of the underground water inrush accident in the underground line No. 7, Guangzhou City subway shield tunneling process, Liu et al. put forward an analytical method for groundwater flow through the shield tunnel face in a confined aquifer [13]. Taking the water inrush accident during the tunneling construction of the Wuhan Metro shield tunnel as an example, Zhao et al. adopted a numerical method to investigate the effect of water inflow from the excavation face on the mechanical performance of segment joints [3]. In fact, the launching-arrival stage of the shield machine consists of eight steps, namely, end soil reinforcement, installation of launching-arrival pedestal, installation of the reaction frame, shield machine approach, shield machine assembly and commissioning, installation of negative ring segments, portal chiseling, and installation of the door seals [14]. The shield tunneling stage mainly has three steps, including excavation of soil by the rotary cutter head, transportation of soil to the belt conveyor by the screw conveyor after soil crushing and drilling, and transportation to the slag transport truck [15]. It can be seen that the launchingarrival stage is more complicated than the construction process of the excavation process. Thus, it is the most dangerous construction stage in subway construction. Once a sudden water inrush occurs, the damage is more serious $[16,17]$.

In summary, previous studies of water inrush in subway shield construction are mainly as follows: (1) previous studies are mainly concentrated on the flooding disaster at the tunneling stage with relatively low risk rather than the water inrush at the high-risk launching-arrival stage; (2) only a simplified model is used to calculate and analyze the influence of water inrush on the overall stress and deformation of the shield tunnel. Therefore, this study focuses on the excavation surface water inflow at the high-risk launching-arrival stage based on the example of Wuhan Metro Line 7 (Figure 1) from the Xiaodongmen to Wuchang railway station section (XW section). The inrush model of the launching-arrival stage of the subway shield was established by utilizing the equivalent refinement modeling technology and ABAQUS simulation analysis with consideration of the fluid--solid coupling effect of water and soil to study the influences of different water head differences on the mechanical and deformation properties of segments and anchors in shield construction under the conditions of water inrush on the excavation surface.

The rest of this article is organized as follows. In Section 2 , the equivalent refinement modeling method and the inrush model parameters of the launching-arrival stage are introduced. The launching-arrival stage of the shield tunneling and the impact of sudden water inrush from the excavation surface on the stress and deformation of the tunnel-forming structure are described and discussed in Section 3. In Section 4, the emergency control standard for soil reinforcement in shield tunneling is proposed under the condition of water inrush from the excavation surface. Finally, Section 5 is a summary of the study conclusions. 


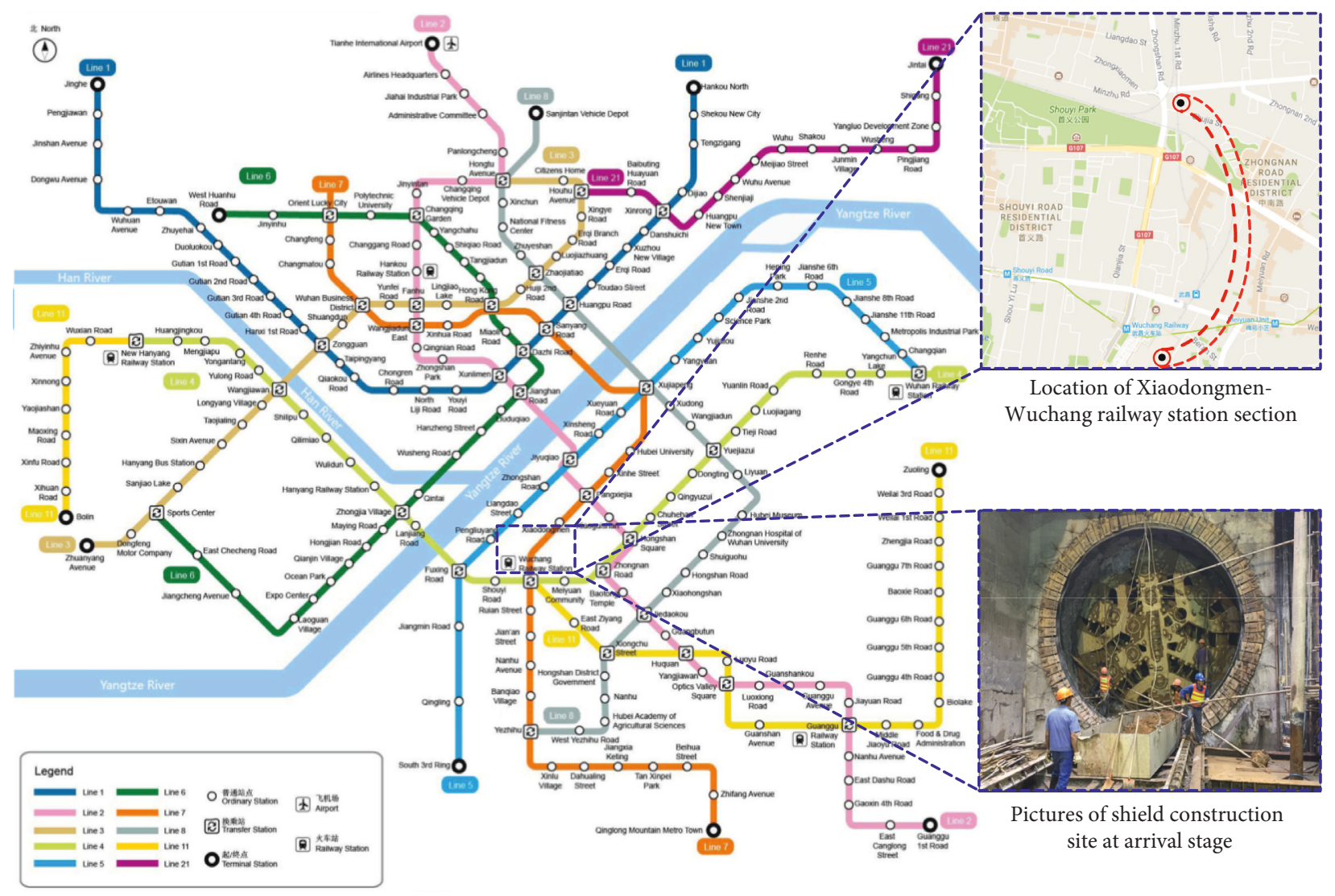

FIgURE 1: Location of the XW section in the Wuhan Metro system.

\section{Establishment of Inrush Model at the Launching-Arrival Stage}

2.1. Introduction to Working Conditions. The tunneling interval between Wuhan Metro Line 7 Xiaodongmen and Wuchang Railway Station Shield Zone (XW interval) passes through the bustling section and important transportation hubs, such as Xiaodongmen Station Overpass, WuhanKowloon Railway, Beijing-Guangzhou Railway, Huanghelou Park, Dadongmen Overpass, and New Beacon International Hotel. The interval is set along the north and south with a covering soil thickness of $10.5 \mathrm{~m}-45.4 \mathrm{~m}$. The length of the left tunnel is $1115.208 \mathrm{~m}$, which is constructed by the Liaoning 33 shield machine, whereas the right tunnel is $1107.169 \mathrm{~m}$ long and constructed by the Komatsu shield machine. The main dimensions and technical parameters of the shield machine are presented in Table 1. The minimum plane curve radius of the interval line is $400 \mathrm{~mm}$ with a line spacing of $12.6 \mathrm{~m}-50.5 \mathrm{~m}$, and the minimum curve radius of the longitudinal section is $3000 \mathrm{~m}$ with a $\mathrm{V}$-shaped slope. A wastewater pumping station is used as the communication channel in the interval. It belongs to the Yangtze River III grade along with the interval. During the arrival of the shield construction, owing to insufficient soil reinforcement, a sudden water inrush accident occurred when the shield machine evacuated the tunnel portal, as shown in Figure 2.

The strata in the XW interval left-line shield crossing area are mainly (10-2) silty clay, (18c-2) medium weathered silty mudstone, (18c-1) strongly weathered silty mudstone, (19c-2) medium weathered quartz sandstone mudstone, (19-2) medium weathered quartz rock fine sandstone, (20a-2) medium weathered silty mudstone, (20b-2) medium weathered argillaceous siltstone, (20c-2) medium weathered silty mudstone, (11-1) fine sand containing cohesive soil, and (11-2) fine and medium sand containing cohesive soil. The geological section of the left-line shield is shown in Figure 3.

The strata in the XW interval right-line shield crossing area are mainly (10-2) silty clay, (18c-1) strongly weathered silty mudstone, (13-2) red clay, (19a-2) medium weathered silty mudstone, (19-2) medium weathered quartzite fine sandstone, (20a-2) medium weathered silty mudstone, (20b2) intermediate weathered argillaceous siltstone, and (11-1) fine sand containing cohesive soil. The geological section of the right-line shield is shown in Figure 4.

The groundwater in the field is divided into three types, namely, upper layer stagnant water, pore confined water, and karst fissure water. The pore confined water is present in the Yangtze River ancient river channel, including (11-1) layer of fine sand containing cohesive soil, (11-2) layer of fine sand containing cohesive soil, and (12) layer of medium and fine sand mixed with gravel pebble, which receives the osmotic recharge of the pressurized water in the surrounding area with a moderate water volume. Karst fissure water mainly occurs in limestone. The karst fissures in the argillaceous limestone are generally concentrated in the karst development and have partial artesian pressure. 
TABLE 1: Overview of shield machines in the XW section.

\begin{tabular}{|c|c|c|c|}
\hline No. & Item & Liaoning 33 shield machine & Komatsu shield machine \\
\hline 1 & Shield type/model & Composite earth-pressure balance/RME254 & $\begin{array}{c}\text { Composite earth pressure balance/ } \\
\text { TM641PMM }\end{array}$ \\
\hline 2 & Diameter of excavation & $6480 \mathrm{~mm}$ & $6480 \mathrm{~mm}$ \\
\hline 3 & Cutter head shield length & $9.62 \mathrm{~m}$ & $9.33 \mathrm{~m}$ \\
\hline 4 & Length & $73.62 \mathrm{~m}$ & $67.28 \mathrm{~m}$ \\
\hline 5 & Weight & $450 \mathrm{t}$ & $450 \mathrm{t}$ \\
\hline 6 & Minimum turning radius & $250 \mathrm{~m}$ & $250 \mathrm{~m}$ \\
\hline 7 & Maximum thrust & $36000 \mathrm{kN}$ & $40018 \mathrm{kN}$ \\
\hline 8 & Rated torque & $6650 \mathrm{kN} \cdot \mathrm{m}$ & $7500 \mathrm{kN} \cdot \mathrm{m}$ \\
\hline 9 & Torque relief & $8320 \mathrm{kN} \cdot \mathrm{m}$ & $9000 \mathrm{kN} \cdot \mathrm{m}$ \\
\hline 10 & Maximum tunneling speed & $100 \mathrm{~mm} / \mathrm{min}$ & $80 \mathrm{~mm} / \mathrm{min}$ \\
\hline 11 & Total equipment power & $1855 \mathrm{~kW}$ & 1402 kW \\
\hline 12 & Cutter head opening rate & $40 \%$ & $38 \%$ \\
\hline 13 & Central opening rate of the cutter head & $50 \%$ & - \\
\hline
\end{tabular}

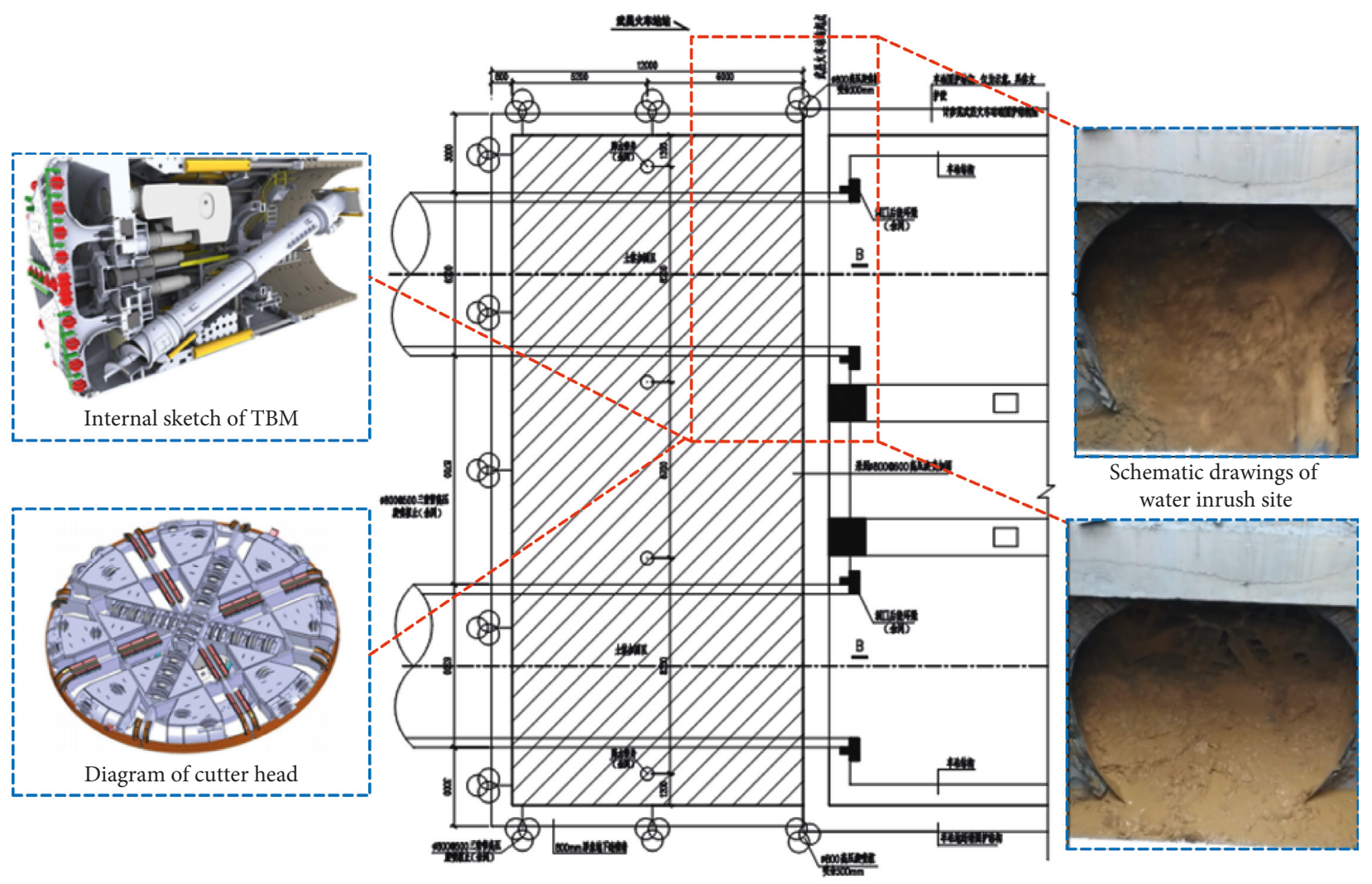

FIgURE 2: Schematic diagram of the surge accident scene in the shield arrival stage at the Wuchang railway station.

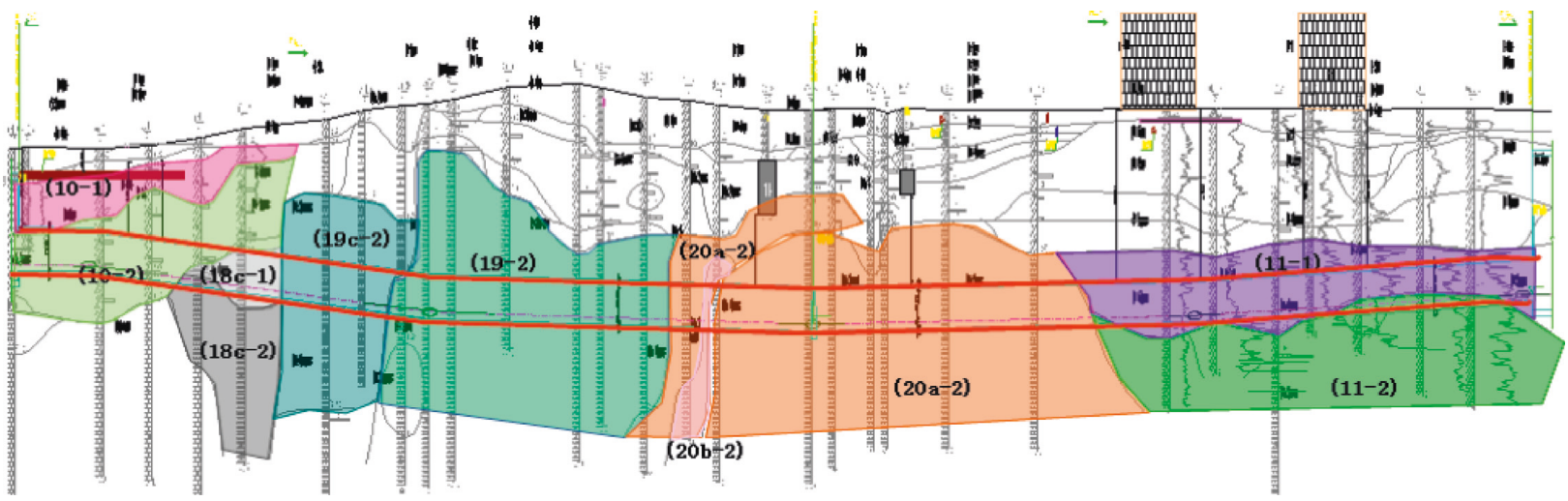

Figure 3: Geological profile of shield crossing on the left line. 


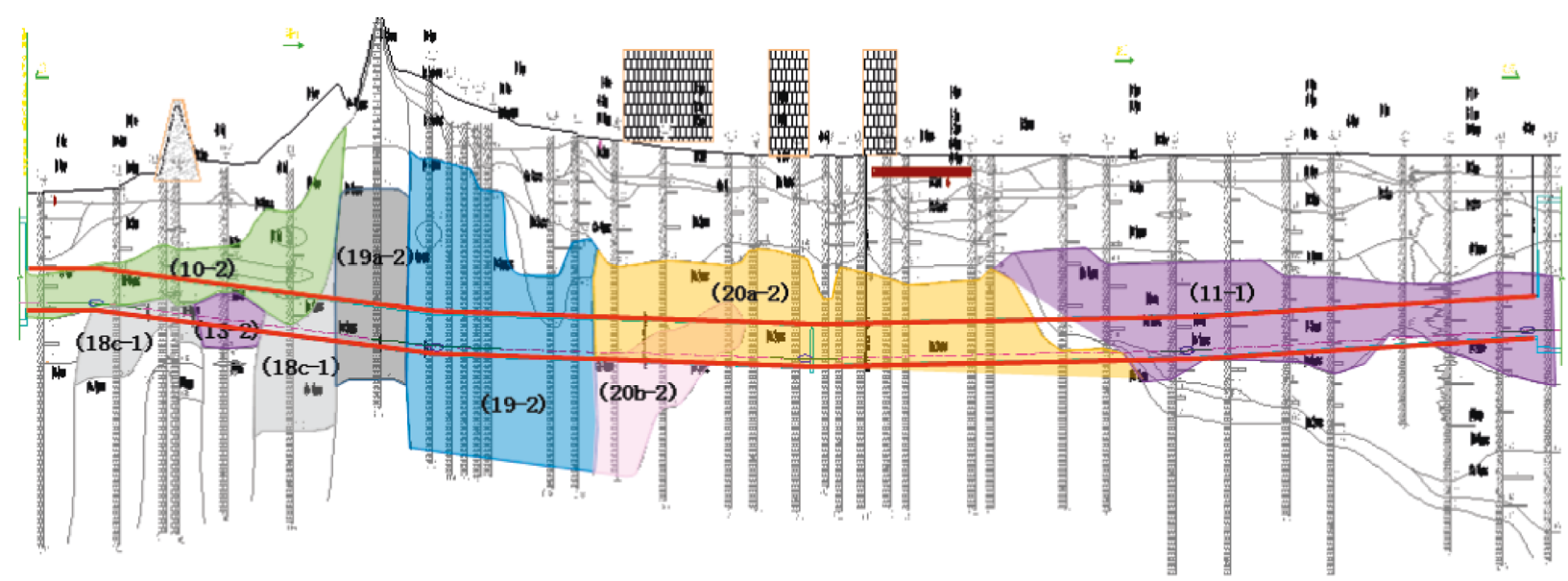

FIGURE 4: Geological profile of shield crossing on the right line.

2.2. Modeling Parameters. The generalized Mises yield criterion cannot reflect the influence of intermediate principal stress on yield and failure, or the yield characteristics caused by simple hydrostatic pressure. In addition, the resulting yield surface is a spigot with a pointed top in the principal stress space. If the stress point is at the ridgeline or on top of the cone, it will cause difficulties in mathematical processing [18]. To overcome the above drawbacks, based on the hexagonal pyramid-shaped and smooth conical yield surface without corners or edges generated from the generalized Mises yield criterion, as well as the influence of intermediate principal stress and hydrostatic pressure, Drucker and Prager proposed the Drucker-Prager model in 1952, which is abbreviated as the D-P yield failure criterion [19]. The functional forms of the D-P yield failure criterion are shown in equations (1)-(3). This model not only has few parameters and simple calculation but also considers the influence of hydrostatic pressure on the yield and strength of materials and the dilatancy of geomaterials [20]. In this article, the constitutive model of the ABAQUS modified DruckerPrager model is used. The yield surfaces of the modified D-P model are divided into three forms on the meridian plane, namely, linear, parabolic, and exponential types [19].

$$
f\left(I_{1}, \sqrt{J_{2}}\right)=\sqrt{J_{2}}-\alpha I_{1}-k=0 .
$$

In the following formulas, $I_{1}$ and $J_{2}$ are the first and second invariants of the stress tensor, respectively. If $\sigma_{1}, \sigma_{2}$, and $\sigma_{3}$ are the maximum and intermediate principal stress, respectively (the compressive stress is positive, whereas the tensile stress is negative), then

$$
\begin{aligned}
& I_{1}=\sigma_{1}+\sigma_{2}+\sigma_{3} \\
& J_{2}=\frac{\left(\sigma_{1}-\sigma_{2}\right)^{2}+\left(\sigma_{2}-\sigma_{3}\right)^{2}+\left(\sigma_{1}-\sigma_{3}\right)^{2}}{6},
\end{aligned}
$$

where $\alpha$ and $k$ are the D-P criterion material parameters, which can be obtained by data analysis of the triaxial test.

The parameters in this model are selected according to the data of the geological exploration of water inrush condition of the shield arrival stage of the Wuchang Railway Station. Subsequently, various mechanical performance parameters of soil mass are sorted out, such as elastic modulus, cohesion, internal friction angle, void ratio, density, and permeability coefficient. Finally, the basic mechanical parameters of the soil in the water inrush condition of the XW interval shield arrival stage are obtained, as shown in Table 2.

The numerical model was established according to the construction data on-site. The model was mainly composed of soil, shield machine, grouting layer, segment, bolt, and soil reinforcement. The shield machine, the grouting layer, and the segment are assumed to be elastic materials. The equal generation layer was used to simulate the time effect of flow paste hardening. The bolt bending diameter at the joint of the segment was $30 \mathrm{~mm}$, and the specific dimensions and basic mechanical parameters of the above components are shown in Table 3. The grouting layer consists of soft and hard grouting layers. According to the specific construction parameters on-site, it was assumed that the average grouting amount per ring was $7 \mathrm{~m}^{3}$. Because of the volume loss caused by the compressibility of the shield tail and the water loss, the grouting volume is larger than the volume of soil. The grouting volume is generally $150 \%-200 \%$ of the excavation gap. Combined with the shield construction site in the XW section, the thickness of the grouting layer of the construction model is assumed to be $0.14 \mathrm{~m}$. According to the gap volume of each soil cycle, the grouting ratio can be calculated as $167 \%$. When grouting, the grouting pressure was applied to the outer cycle of the segment and the inner wall of the soil to simulate the grouting pressure at the shield tail.

2.3. Equivalent Refinement Modeling. In the actual process of design and construction of subway shield tunnel, it is often required to control the following two aspects: (1) identification of the dangerous working conditions and dangerous locations that may be damaged in the system according to the macroscopic change pattern of the overall structure of the project under various working conditions and (2) identification of the microscopic local structure of the system, especially the change patterns of stress and strain on the key and complex local structures under various working conditions, such as the nodes and joints of the structure. 
TABLE 2: Basic parameters of soil mass in the launching-arrival stage of shield tunneling in the XW interval.

\begin{tabular}{|c|c|c|c|c|c|c|c|c|}
\hline Name of soil layers & $\begin{array}{l}\text { Compressive } \\
\text { modulus }(\mathrm{kPa})\end{array}$ & $\begin{array}{c}\text { Elastic } \\
\text { modulus } \\
(\mathrm{kPa}) \\
\end{array}$ & $\begin{array}{l}\text { Poisson } \\
\text { ratio }\end{array}$ & $\begin{array}{l}\text { Cohesion } \\
(\mathrm{kPa})\end{array}$ & $\begin{array}{l}\text { Internal friction } \\
\text { angle }\left({ }^{\circ}\right)\end{array}$ & $\begin{array}{l}\text { Void } \\
\text { ratio }\end{array}$ & $\begin{array}{c}\text { Saturation } \\
\text { density } \\
\left(\mathrm{kN} / \mathrm{m}^{3}\right)\end{array}$ & $\begin{array}{c}\text { Permeability } \\
\text { coeffcient } \\
(\mathrm{m} / \mathrm{s})\end{array}$ \\
\hline Miscellaneous fill 1-1 & 1500 & 879 & 0.36 & 8 & 18 & 0.69 & 18.5 & $5.0 * 10^{-7}$ \\
\hline Silty clay $10-1$ & 24300 & 19215 & 0.28 & 65 & 29 & 0.67 & 19.7 & $1.5 * 10^{-9}$ \\
\hline Silty clay $10-1 \mathrm{a}$ & 46000 & 8072 & 0.31 & 36 & 10 & 0.66 & 19.5 & $1 * 10^{-9}$ \\
\hline Silt fine sand 11-1 & 40900 & 19039 & 0.29 & 16 & 24 & 0.43 & 19.7 & $1 * 10^{-9}$ \\
\hline $\begin{array}{l}\text { Strongly weathered } \\
\text { mudstone } 18 \mathrm{c}-1\end{array}$ & 45000 & 81940 & 0.3 & 48 & 30 & 0.35 & 21 & $1 * 10^{-9}$ \\
\hline Mudstone 20a-2 & 500000 & 371429 & 0.3 & 50 & 19 & 0.30 & 22.5 & $1 * 10^{-9}$ \\
\hline
\end{tabular}

TABLE 3: Basic parameters of components in the launching-arrival stage of shield tunneling in the XW interval.

\begin{tabular}{lccccc}
\hline Model component & Unit weight $\left(\mathrm{kN} / \mathrm{m}^{3}\right)$ & Elastic modulus $(\mathrm{MPa})$ & Poisson ratio & External diameter $(\mathrm{m})$ & Internal diameter $(\mathrm{m})$ \\
\hline Shield machine block & 78.5 & 210000 & 0.125 & 6.4 & 6.2 \\
Over excavation soil & 20 & 0.8 & 0.2 & 6.48 & 6.4 \\
Grouting layer (soft) & 20 & 7 & 0.2 & 6.48 & 6.2 \\
Grouting layer (hard) & 25 & 50 & 0.3 & 6.48 & 6.2 \\
Bolt & 78.5 & 210000 & 0.125 & 0.03 & - \\
Segment & 30 & 30000 & 0.3 & 6.2 & 5.5 \\
Soil reinforcement & 20 & 100 & 0.3 & - & - \\
\hline
\end{tabular}

According to the characteristics of the finite element, the degree of discretization of the model significantly impacts the calculation results and computational efficiency. Therefore, in the traditional numerical analysis, different finite element models are generally established to study the macroscopic and microscopic laws of the structure. When building a macroscopic model, the detailed structure is often simplified or even ignored. For instance, the continuous overall model commonly used in the numerical analysis of traditional subway tunnels neglects all joint structures of the subway shield tunnel. As a result, the tunnel model excluding the joint cannot fully reflect the actual deformation and stress of the shield tunnel under the condition of water inrush on the excavation surface, which in turn does not express the microstructural law. The analysis of the detailed structure is generally only to establish the model of the microstructure at a local extent. The analysis of the changing pattern is carried out by assuming the state of force or deformation. However, the force or deformation state under real working conditions of the detailed structure and even the boundary conditions are hardly represented by the assumed force, deformation, and boundary state. At the same time, the considerable longitudinal dimension of the subway shield tunnel structure determines the huge computational model of the underground structure foundation system. If the detailed structure is fully considered, the number of refined model units would be too large. The calculation cost is huge, and cannot even be completed. It is challenging to establish a refined model on an ordinary computer for shield tunnel with a length of hundreds of meters or even tens of meters, which makes it impossible to study the longitudinal pattern of the subway shield tunnel structure under the conditions of water inrush. Therefore, to achieve the simultaneous study of the stress and deformation characteristics of the shield tunnel and segment joint structure under the condition of water inflow from the excavation surface, the most complete method is to establish an equivalent refinement model that can describe both the macroscopic overall behavior and microscopic behavior of the structure.

In fact, to reduce the calculation time and avoid the cost of the full-scale model, development of an equivalent refinement modeling technology provides an efficient alternative to modeling, which solves the contradiction among model size, grid size, and affordable computing cost [3]. The equivalent refinement modeling has a wide range of macroscopic scales and can observe the mesoscopic state of the local structure. Therefore, the numerical analysis was performed by the equivalent refinement modeling technique, and the segment model outside the drainage area was equivalently simplified by the relatively coarse grid. The segments in the drainage area were equivalently refined, and bolt-segment connections and mortise and tenon structures are also considered. The equivalent and refinement parts of the model determine the contact form of the segment circumferential joint. To ensure accurate calculation and avoid transitional conversion between two meshes with different fineness, the equivalent refined segment-bolt structure was adopted in the drainage area to obtain the internal force of the segment and bolt, as shown in Figure 5(a). In addition, the equivalent model was used to determine the critical section $\mathrm{D}$ affected by the gushing water on the excavation face, as shown in Figure 5(b) of the deformation nephogram of the tunnel.

The equivalent refinement simulation models of the shield arrival stage and other stages are shown in Figure 6. From top to bottom, the soil is divided into five layers, namely, mixed fill, silty clay, strongly weathered mudstone, medium weathered mudstone, and hard mudstone. The width, depth, and length of the shield are 120,50, and $96 \mathrm{~m}$, respectively. To reduce the friction between the shield and 


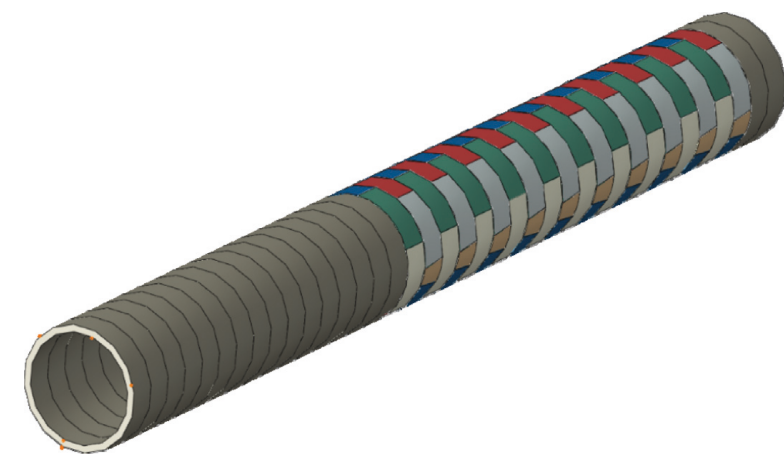

(a)

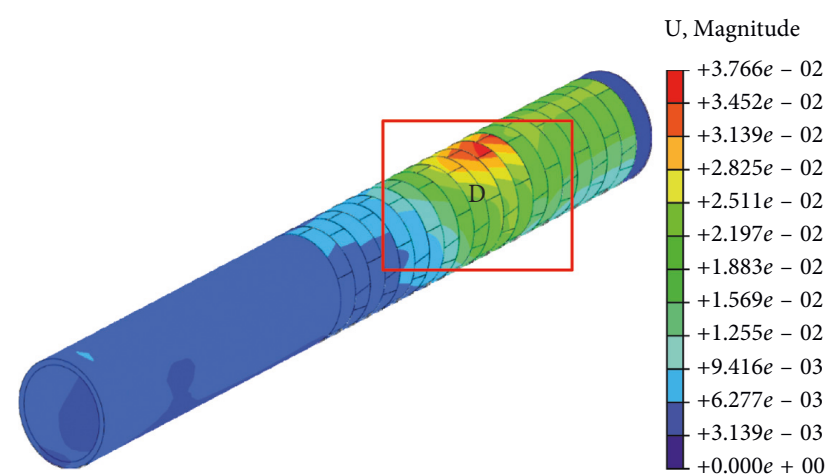

(b)

Figure 5: Equivalent refinement simulation model. (a) Critical section of the tunnel model under water inrush. (b) Section D of the stimulated model.

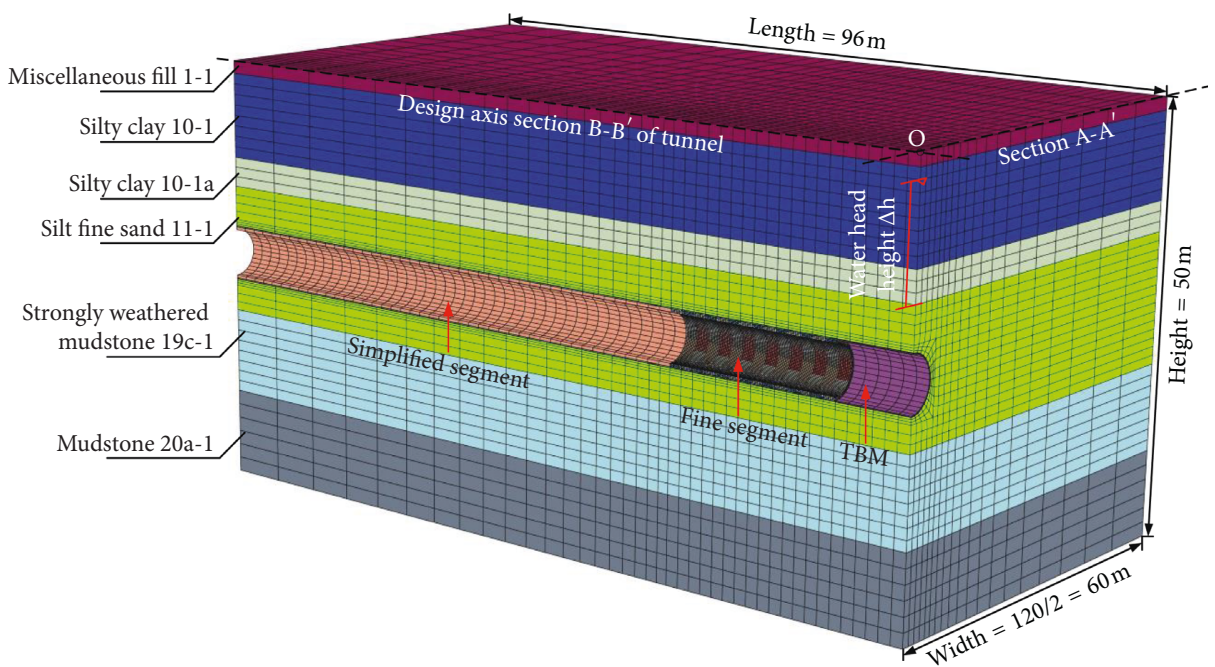

FIGURE 6: Simulated model of the launching-arrival stage of shield tunneling in the XW interval.

the soil and control the turning of the shield, it is inconvenient to adopt a three-dimensional stress release protocol because of the soil over-excavation in the shield during the actual construction process, as well as the inconvenience of ABAQUS to simulate the cone of the shield body. Therefore, a thin over-excavation layer on the outer wall of the shield was introduced in this model to simulate the over-excavation of the soil. According to the geometrical dimensions of the shield, the cutter head outer diameter of $6.48 \mathrm{~m}$ and the shield tail outer diameter of $6.4 \mathrm{~m}$, the thickness of the over-excavation was set to $0.04 \mathrm{~m}$. During the excavation process, the influence of the conicality of the shield can be simplified, and the stress of the surrounding rock can be released to a certain extent. As a result, the outcome of the numerical simulation is closer to the actual result [11].

The model simulates each segment by using the solid element, in which the beam element was simulated the bolt. The preload was used to simulate the state of the segment under the high-strength bolt connection. The preload under actual condition was $30 \mathrm{kN}$. Similarly, other factors such as the grouting layer and the surrounding rock were simulated with the solid element. Each segment consists of three standard blocks A1, A2, and A3, two adjacent blocks B1 and $\mathrm{B} 2$, and a capping block $\mathrm{K}$. The width and thickness of each segment were $1.5 \mathrm{~m}$ and $0.35 \mathrm{~m}$, respectively. The outer and inner diameters were 6.2 and $5.5 \mathrm{~m}$, respectively. The space between the circles was built with a break joint assembly method. The bolt consisted of 16 longitudinal bolts (M30) and 12 circumferential bolts (M30) with a bolt section diameter of $30 \mathrm{~mm}$, as shown in Figure 7(a). Assuming that the concrete is a linear elastic material and given the concave and convex grooves of the circumferential joint, hard contact was adopted for the positive joint of the segment. Coulomb friction contact was used on the tangential direction with a tangential friction factor of 0.62 , and the bending bolt was embedded in the segment [11]. To prevent the components from "piercing" each other, hard contact and Coulomb frictional contact were also adopted for the tube and the grouting layer with a tangential friction factor of 0.7. The external paste was connected to the soil with "Tie," as shown in Figure 7(b). 


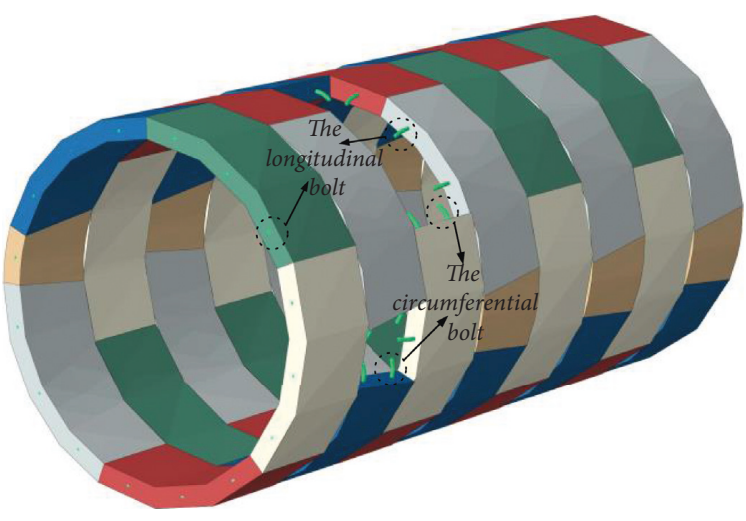

(a)

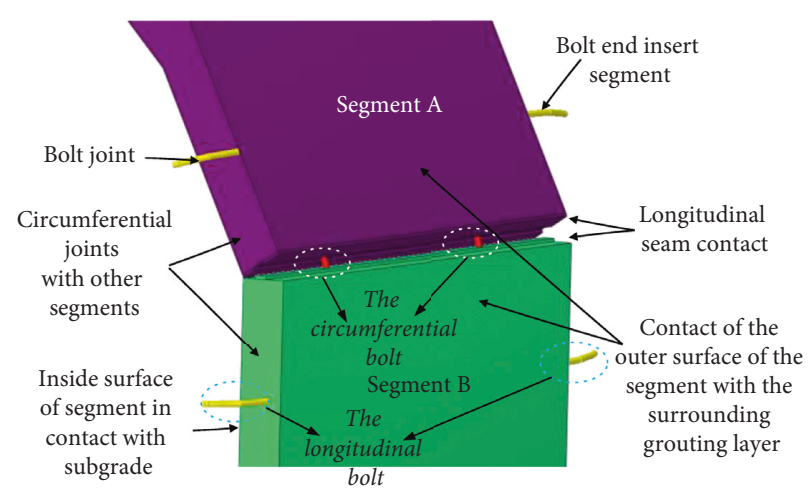

(b)

FIGURE 7: Contact relationship between grouting layer, segment, and surrounding rock. (a) Segment lining model and (b) contact relationship.

2.4. Model Boundary and Simulation Process. The fluid-solid coupling effect of water with soil is simulated with "the transient analysis of soil" in ABAQUS. The segment has an optimal sealing effect because of the faster construction speed of the site shield. Since the miscellaneous backfill and silty clay have a relatively low permeability coefficient than the fine sand layer, it is assumed that the miscellaneous backfill and silty clay do not have seepage permeability. Different heads are set for the upper water head of the fine sand layer to study the influence of the head difference change on the surface subsidence and internal force of the segment and anchor bolt. The bottom of the model is a fixed boundary, which constrains the normal displacement on the side of the model, whereas the top is a free surface. When the shield machine reaches the portal, owing to the constraint of the concrete reinforcement layer, the normal displacement deformation of the soil reaching the portal is negligible. In addition, the normal soil reaching the tunnel portal is constrained to simulate the construction process of the shield machine reaching the tunnel portal stage by removing the soil reaching the tunnel portal and the normal boundary. During the excavation process, the supporting force for the excavation surface provided by the shield machine and the synchronous grouting pressure at the shield tail are set. The supporting force for the excavation face was $400 \mathrm{kPa}$, which linearly increased with depth at a gradient increment of $13 \mathrm{kPa} / \mathrm{m}$. It was greater than the lateral static pressure imposed by the water and soil combined force. According to the field test data, the grouting pressure at the shield tail was $150-300 \mathrm{kPa}$, with a maximum grouting pressure of $300 \mathrm{kPa}$. However, the monitoring data are only limited to the grouting pressure at the paste pumping tube. Because of the diffusion filling of the paste in the shield tail gap, the grouting pressure will have certain dissipation. According to experience, it is assumed that the grouting pressure is $200 \mathrm{kPa}$, which acts uniformly on the soil and the outer wall of the segment.

To eliminate the boundary effect of the model, the whole ring segment and the grouting layer were adopted for the first 40 segments. After the stress was balanced, the simplified segment and the grouting layer for the first 40 rings were uniformly added. The refined segments were installed at the distance of the 20th ring to the portal and to simulate the influence of water inrush on surface subsidence and internal force of the segment and anchor bolt after the tunnel machine evacuates the portal. The model consisted of a total of 17 analysis steps; each analysis step was 1 hour. The specific simulation steps are as follows:

(1) When the shield machine body entered the soil entirely, the shield body was $9 \mathrm{~m}$ long, and the 9-m soil was passivated simultaneously. After the supporting force for excavation face was added, the outer ring (over-excavation) of the shield machine was connected with soil mass via "Tie," as shown in Figure 8(a).

(2) The front shield ring was activated while the rear shield ring was deactivated. In the meantime, lining segments and equivalent grouting layer were added. With the application of the grouting pressure to the inner wall of the soil and the outer ring of the lining, the retaining surface support force was applied to ensure the stability of the excavation surface. To simplify the calculation, the "Tie" constraint was applied to the exterior of the paste and the soil, as well as the inner part of the paste and the outer ring of the segment, as shown in Figure 8(b).

(3) When the four rings of the grouting layer were supported, the lasting length of grouting pressure was $6 \mathrm{~m}$. At this time, the paste exhibited softened flow with a paste strength of $7 \mathrm{MPa}$, as shown in Figure 8(c).

(4) After the segment contained 4 rings, the material parameters of the paste were adjusted to increase the elastic modulus to $50 \mathrm{MPa}$ to simulate the hardening of the paste at the rear of the tunnel and eliminate the grouting pressure. At this time, the segment contained eight rings, and the rear of the segment contained four-ring softened paste and four-ring hardened paste, as shown in Figure 8(d). 


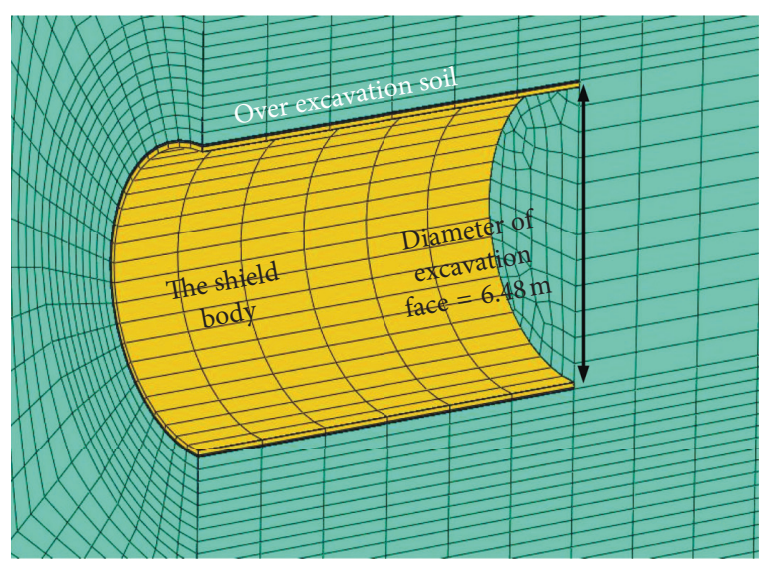

(a)

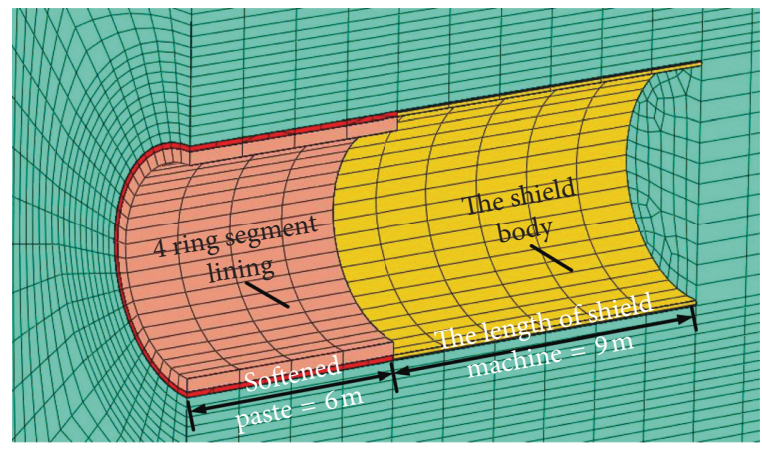

(c)

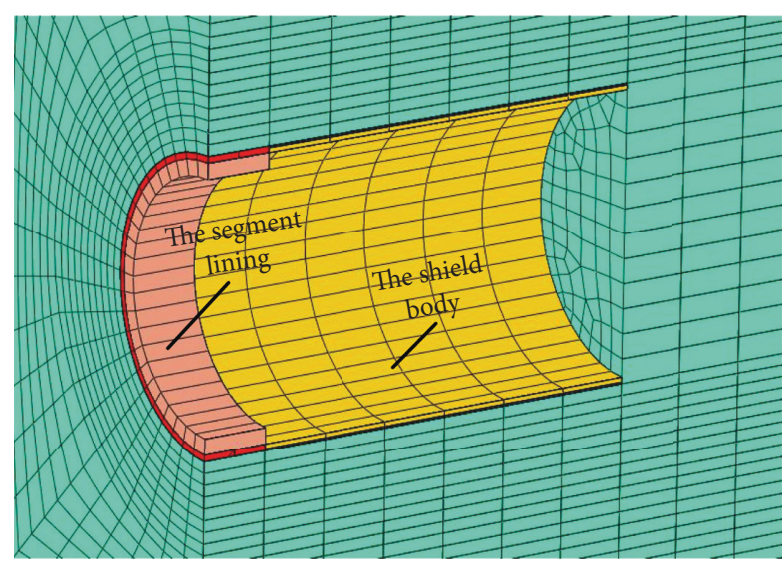

(b)

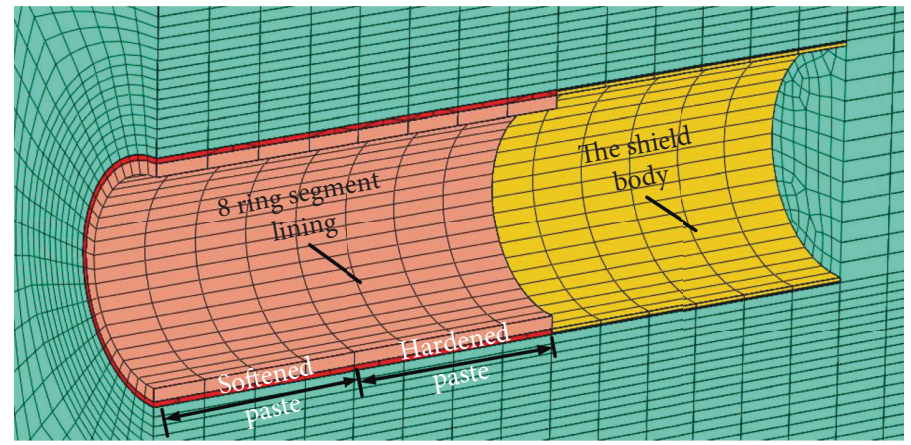

(d)

Figure 8: Numerical simulation of shield tunnel excavation. (a) Shield machine body enters the soil, (b) segment and tail grouting, (c) segment and tail grouting, and (d) segment and hardened paste.

(5) When the shield machine entered the last ring soil, inactivation of the soil and elimination of the last normal constraint boundary of the soil were used to simulate the shield machine reaching the tunnel portal. At the same time, a free drainage boundary (the pore water pressure is set to 0 ) was applied to the soil surrounding the shield machine $(6 \mathrm{~m}$ total) to simulate a large number of sudden inrushes when the shield machine reached the tunnel portal.

\section{Analysis Result of the Inrush Model at the Launching-Arrival Stage}

3.1. Influence of the Most Unfavorable Head Difference $\Delta$ h on the Segment, Anchor, and Surface Subsidence. Cheng et al. [21-23] reported that soil properties, shield segment dimension, depth of burial, and related parameters of lubrication drive significantly impacted the thrust of shield machines or pipe jacking machines. In the same way, in the case of water inrush on the excavation face of the shield construction, the thrust of the shield machine will also be affected. Ye et al. [24] found that under the conditions of water inrush on the excavation surface, it was necessary to increase the thrust of the shield machine to maintain the stability of the excavation surface. However, only increasing the thrust of the shield machine (i.e., the supporting force on the excavation surface) cannot fundamentally solve the problem of significant stress and surface subsidence of the existing shield tunnel segment. When the shield machine excavated in an enriched aquifer with high water pressure, the adjustment of water discharge on the excavation surface could effectively control the stress and surface subsidence of the existing shield tunnel segment [24].

Therefore, according to the water discharge from small to large (the change of the head difference from small to large) of a water inrush accident at the arrival stage of the XW interval shield, the head differences $\Delta h$ of the excavation surface were set at $4.5,7.5,10.5$, and $13.5 \mathrm{~m}$ to reflect four different working conditions and the dynamic evolution process of water inrush on the excavation surface. The equivalent refinement simulation of the segments and bolts was carried out to analyze the influence of the head difference of the excavation surface on the surface subsidence and the internal forces of the segments and bolts. It was found that the most unfavorable water inrush conditions were the drainage length of 6 rings or 9 meters, the drainage time of each ring at $10 \mathrm{~h}$, and the head difference of $\Delta h=13.5 \mathrm{~m}$.

In the XW interval shield construction, in the case of water inrush when the shield machine evacuated the tunnel portal, the sudden water inrush condition, the head difference of $13.5 \mathrm{~m}$ was set as the most unfavorable water inrush condition. The dangerous section $\mathrm{A}-\mathrm{A}^{\prime}$ was defined as the position of the last segment of the shield tunnel (all 
relevant simulation analyses of this dangerous section were conducted in this study) when the shield machine evacuated the tunnel portal, as shown in Figure 9. When there was a large amount of water in the tunnel portal, the surface subsidence at the tunnel portal was significant, and the maximum value of the dangerous section $A-A^{\prime}$ reached $83 \mathrm{~mm}$. In particular, a small amount of collapse occurred at the top of the tunnel, as shown in Figure 8.

Under the most unfavorable water inrush conditions of head difference at $13.5 \mathrm{~m}$, it can be seen from Figure 10 that when there was a large amount of water in the portal, the tunnel segment showed a downward pressing tendency. The last segment next to the shield tunnel portal was the dangerous section $\mathrm{A}-\mathrm{A}^{\prime}$, in which the deformation and stress of the segment were greater than those of the adjacent penultimate segment. By analogy, it can be seen that the deformation and stress of the segments and bolts farther away from the gushing conditions of the portal were much smaller. Figure 11 shows that the maximum extrusion deformation of the segment at the dangerous section $A-A^{\prime}$ reached $42.7 \mathrm{~mm}$, which is very likely to cause the hazard of segment crushing failure. Figure 12(a) shows that the maximum tensile stress of the segment was $10.5 \mathrm{MPa}$, which exceeds the ultimate tensile strength of C50 concrete of $5 \mathrm{MPa}$ [3], indicating that the segment has cracked. Figure 12(b) shows the maximum stress nephogram of the segment that possessed a maximum value of $26.4 \mathrm{MPa}$.

Figure 13 is a diagram showing the internal force of the bolt. Specifically, Figure 13(a) is the bolt tension and Figure 13(b) is the bolt shear. When the head difference of the most unfavorable water inrush condition was $13.5 \mathrm{~m}$, the tensile force of the connecting bolt at the critical section $\mathrm{A}-\mathrm{A}^{\prime}$ was $172.3 \mathrm{kN}$ and the shearing force was $224.5 \mathrm{kN}$. The shear force exceeded the ultimate shear strength of the M30 bolt $215 \mathrm{kN} \mathrm{[3],} \mathrm{and} \mathrm{the} \mathrm{bolt} \mathrm{exhibited} \mathrm{yield} \mathrm{damage.}$

Figure 14 shows the trend of the internal forces of the segments and bolts with different head differences. It can be seen from the figure that when the four head differences $\Delta h$ were $13.5 \mathrm{~m}, 10.5 \mathrm{~m}, 7.5 \mathrm{~m}$, and $4.5 \mathrm{~m}$, respectively, the internal forces of the segments and bolts increased with the increase in drainage time. In other words, under the same drainage time, the higher the head difference, the larger the internal force value of the segments and bolts, which increases the risk of tube misalignment and extrusion cracking. Specifically, when the head difference of the most unfavorable water inrush condition was $\Delta h=13.5 \mathrm{~m}$, the maximum deformation, the maximum tensile stress, and the maximum compressive stress of the segment were $42.7 \mathrm{~mm}$, 10.1 $\mathrm{MPa}$, and $26.5 \mathrm{MPa}$, respectively. In the meantime, the maximum tensile stress and shear force of the bolt were $172.3 \mathrm{kN}$ and $224.5 \mathrm{kN}$, respectively. The internal force of the segment and bolt at the dangerous section $\mathrm{A}-\mathrm{A}^{\prime}$ mainly exhibited the following distribution patterns: (1) For the local compressive stress of the concrete at the vault of the segment, the effect of the amount of water on the excavation face was greater than that of the circumferential joint. The influence of the overall vertical convergence of the segment caused the maximum tensile stress of the segment concrete to appear outside the tunnel arch waist and inside the

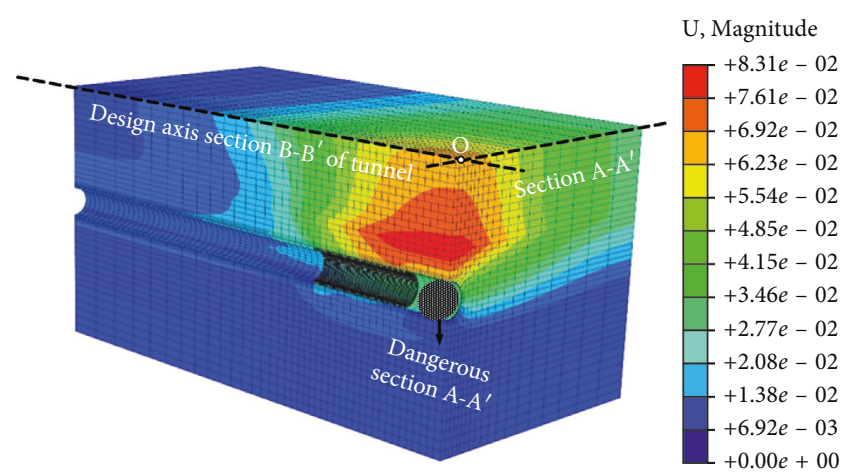

Figure 9: The local area of water inrush on the area excavation surface at the shield arrival stage.

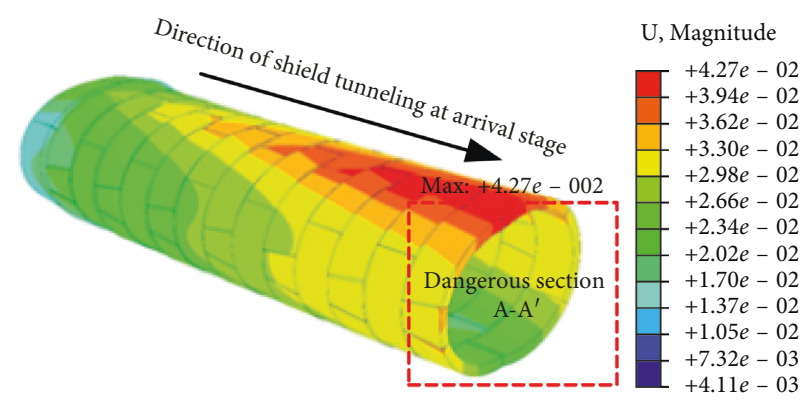

FIGURE 10: Extrusion deformation of segment (magnification 50 times).

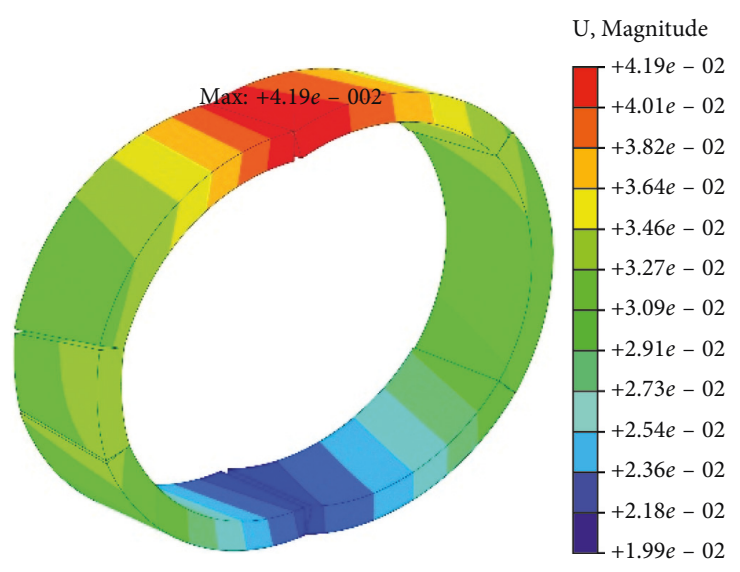

FIgURE 11: Deformation nephogram of the critical section $A-A^{\prime}$ of the tunnel segment at the shield arrival stage.

vaulted arch. (2) Due to the large opening space of the longitudinal joints of the tunnel vault and the arch bottom, the axial force of the hoop bolt was dramatically increased. In the meantime, the increasing misalignment of the pipe caused the shearing force of the longitudinal bolt to increase significantly.

When the tunnel reaches the portal, a large amount of water inrush will cause surface subsidence. When the land surface shows large uneven subsidence, it will easily lead to surface subsidence. Figure 15 shows a comparison of the trend of the subsidence value of the $\mathrm{A}-\mathrm{A}^{\prime}$ section surface with the water inrush time under four different head 


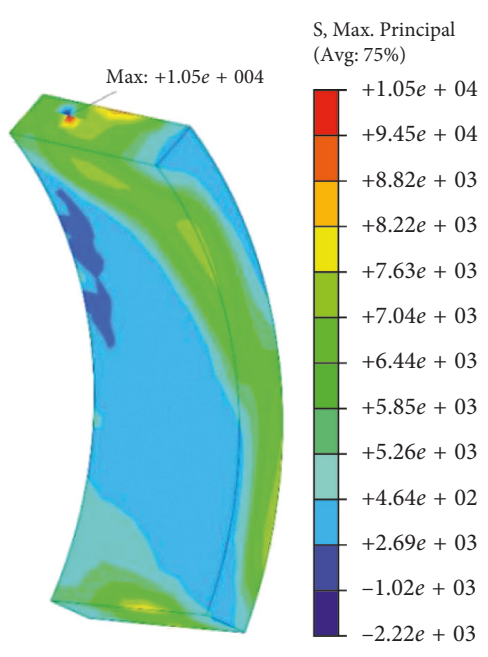

(a)

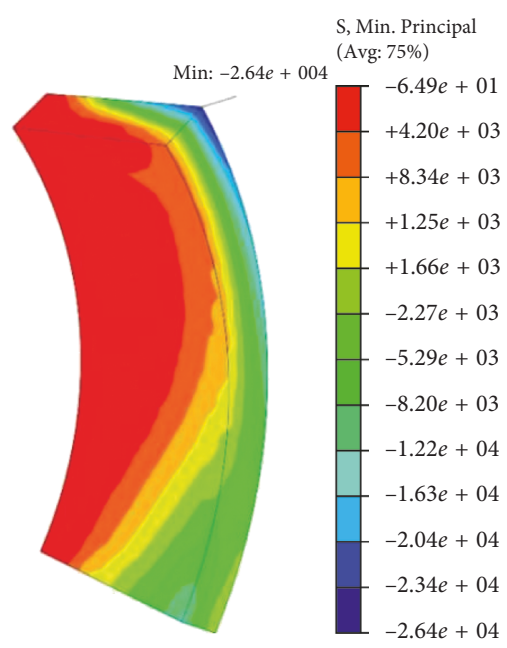

(b)

Figure 12: Maximum stress nephogram of the segment. (a) Tensile stress nephogram. (b) Compressive stress nephogram.

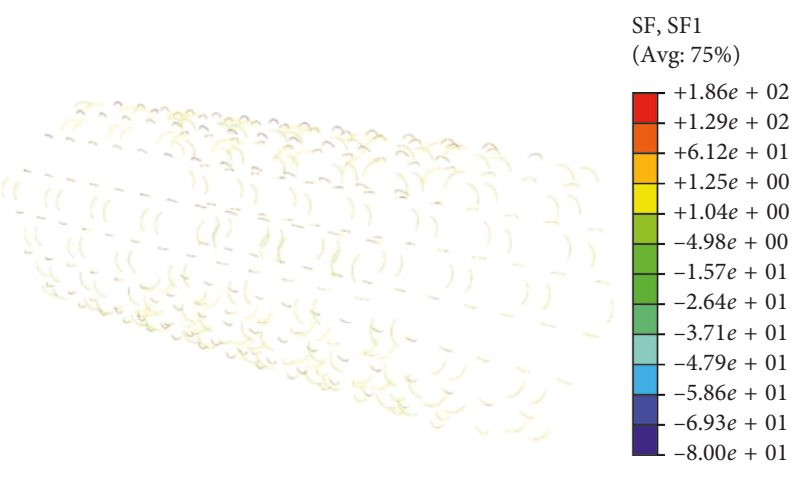

(a)

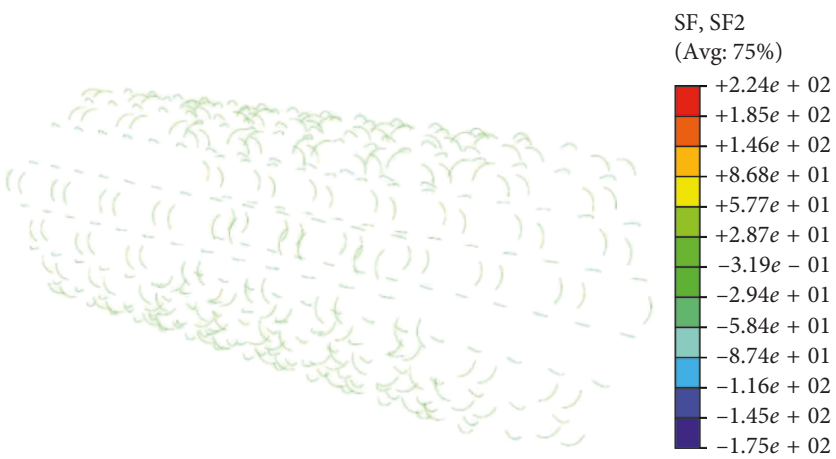

(b)

Figure 13: Internal force nephogram of bolts. (a) Bolt tension. (b) Bolt shear.

differences. It can be seen from the figure that a large settling tank appeared on the land surface as the water rushing time increases. Among them, intersection point $\mathrm{O}$ of the $\mathrm{A}-\mathrm{A}^{\prime}$ section and the tunnel design axis section $\mathrm{B}-\mathrm{B}^{\prime}$ possessed the maximum surface subsidence value. Figure 16 compares the final settling tanks of the A- $\mathrm{A}^{\prime}$ section with four head differences. It can be seen from the figure that when the head difference $\Delta h=13.5 \mathrm{~m}$ was the most unfavorable water inrush condition, the maximum deformation value of the surface subsidence tanked at the intersection point of the A- $\mathrm{A}^{\prime}$ section, and the tunnel design axis section $\mathrm{B}^{-\mathrm{B}^{\prime}}$ was $64.9 \mathrm{~mm}$, which far exceeds the construction and acceptance specification of the subway railway construction, $30 \mathrm{~mm}$ [25] (Supervision 2004), thus having a high risk of surface collapse.

\subsection{Relationship between Internal Force-Deformation of} Segments and Bolts and Different Head Differences $\Delta h$. According to the corresponding numerical calculation results of the internal force-deformation of the segments and bolts and the different head differences $\Delta h$ in the water inrush model of the shield at the launching-arrival stage, the relationship between the maximum deformation of the segment and the different water heads $\Delta h$ on the excavation surface fitted by MATLAB is shown in Figure 17(a). The functional relationship can be expressed as shown in equation (4). Similarly, the relationship between the different head difference $\Delta h$ of the excavation face and the maximum tensile stress, and the maximum compressive stress of the segment concrete is shown in Figures 17(b) and 17(c). The functional relationship is as shown in equation (5). The relationship between the different head difference on the excavation face and the maximum axial force $N$, and the maximum shear force $Q$ of the segment connection bolt is shown in Figures 17(d) and 17(e). The functional relationship is as shown in formula (6).

$$
\begin{gathered}
u=2.4304+0.5281 \cdot e^{\Delta h /(1.0878 \times 10)}, \\
\left\{\begin{array}{l}
\sigma_{t}=-5.0871+9.4568 \cdot e^{\Delta h /(2.8049 \times 10)} \\
\sigma_{p}=-5.0925 \times 10+6.8566 \times 10 \cdot e^{\Delta h /\left(1.1116 \times 10^{2}\right)},
\end{array}\right. \\
\left\{\begin{array}{l}
N=-6.6423 \times 10^{1}+7.1112 \times 10^{1} \cdot e^{\Delta h /\left(3.4516 \times 10^{1}\right)} \\
Q=-5.7981 \times 10^{1}+1.8031 \times 10^{2} \cdot e^{\Delta h /\left(3.0328 \times 10^{1}\right)},
\end{array}\right.
\end{gathered}
$$




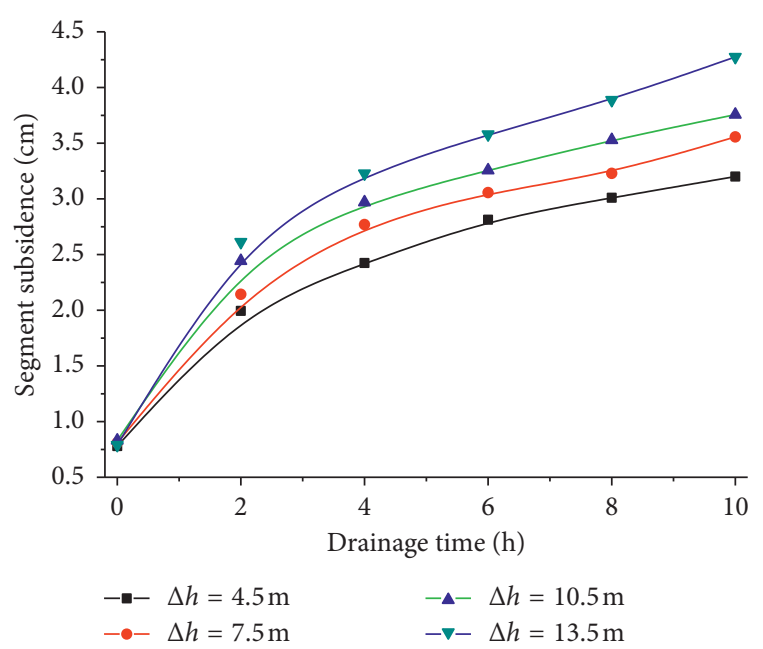

(a)

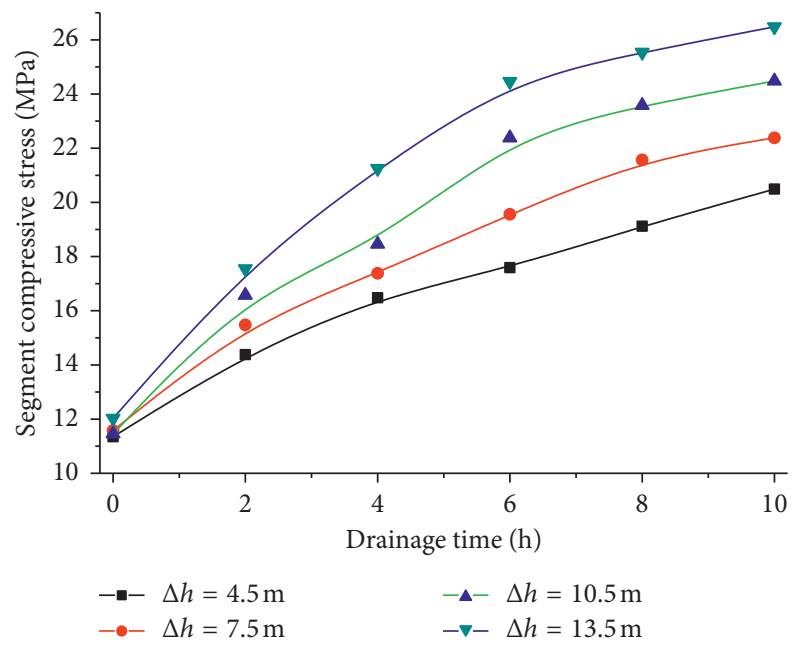

(c)

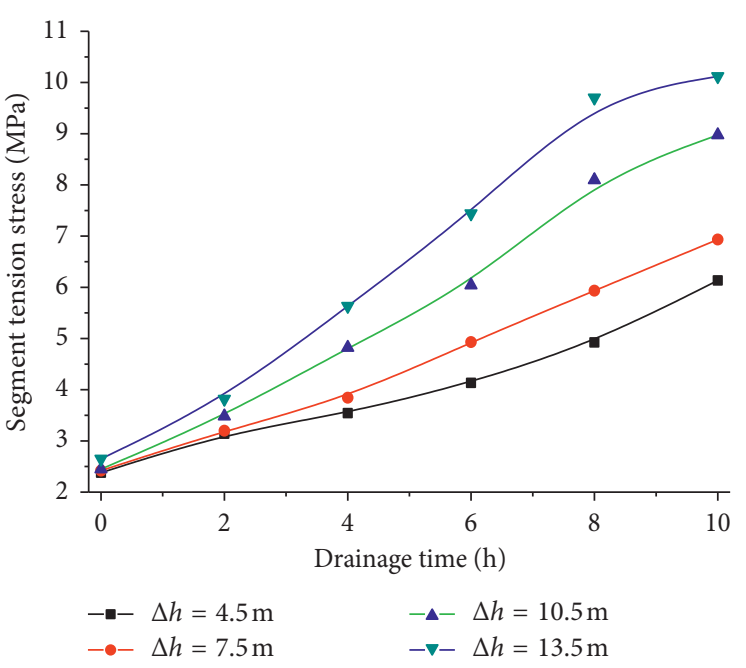

(b)

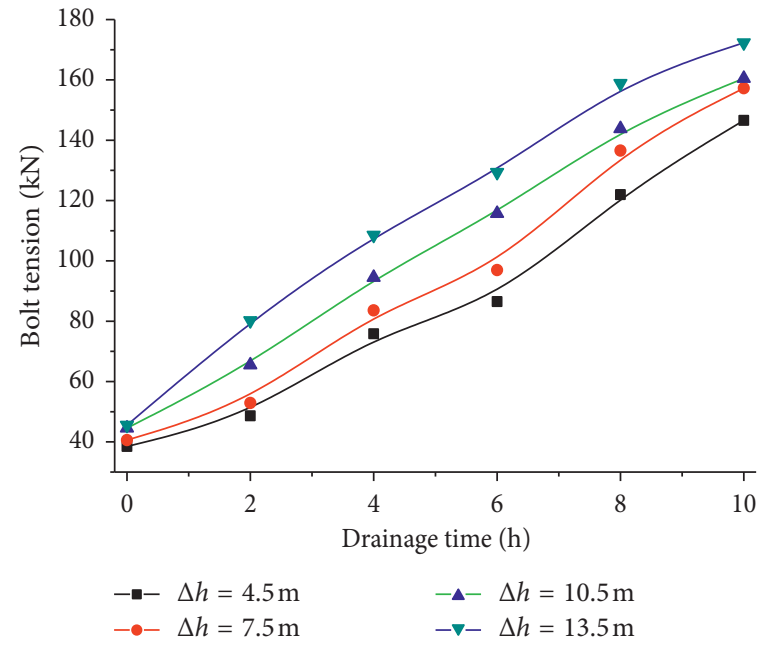

(d)

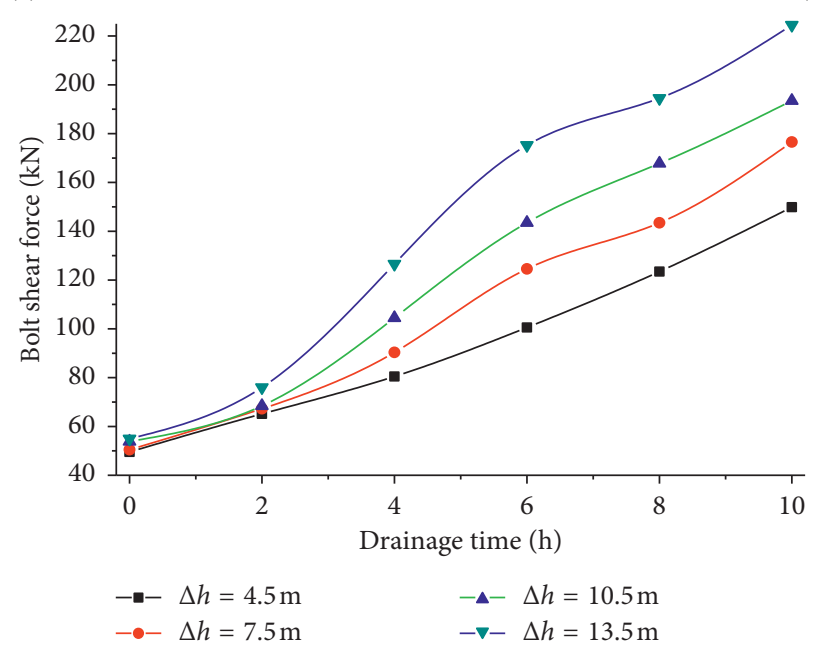

(e)

Figure 14: Variation of the deformation and internal force of the segment and the internal force of the bolt with the water inrush time. (a) Maximum deformation of the segment. (b) Maximum tensile stress of the segment. (c) Maximum compressive stress of the segment. (d) Maximum tensile force of the bolt. (e) Maximum shear force of the bolt. 


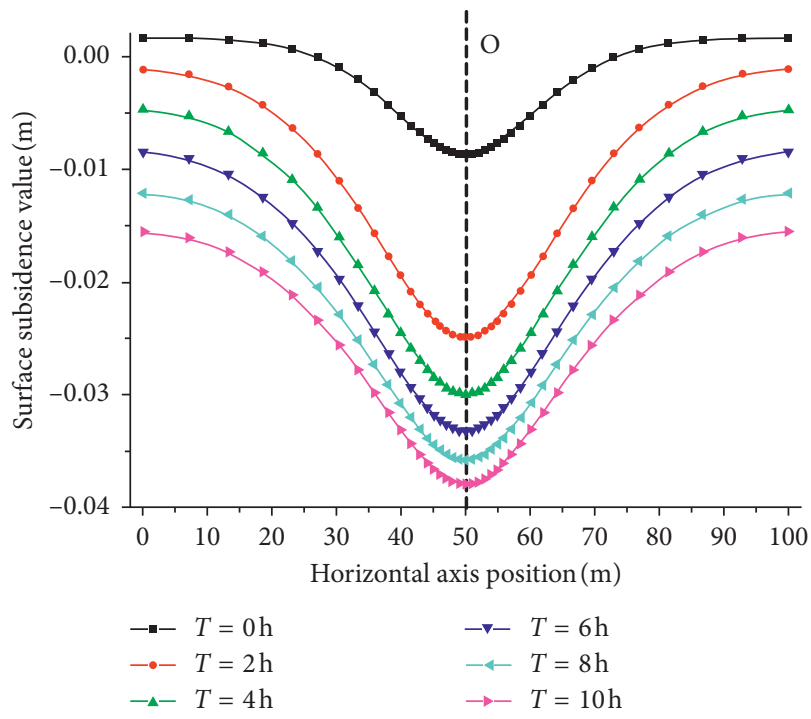

(a)

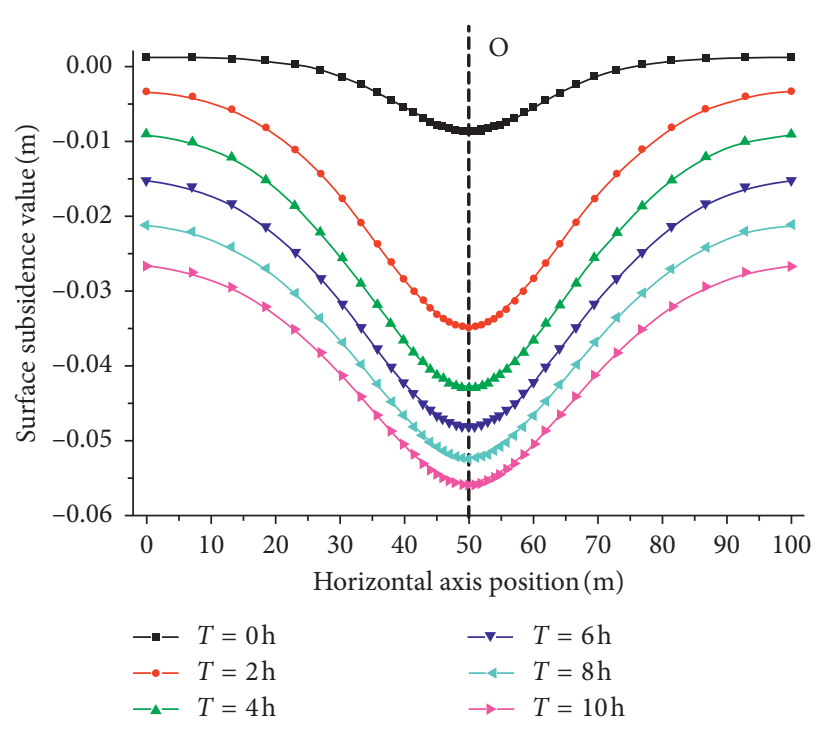

(c)

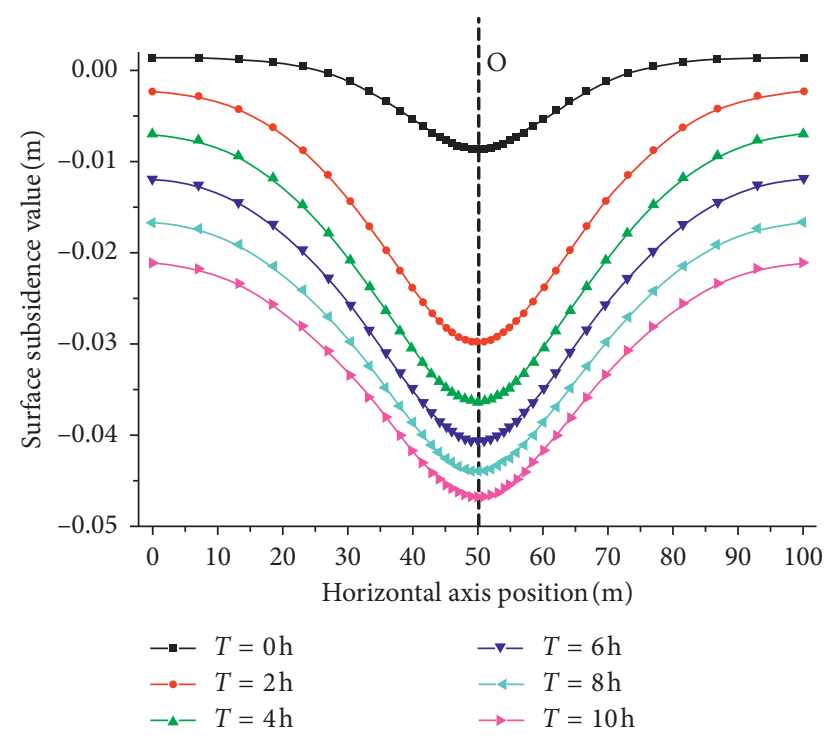

(b)

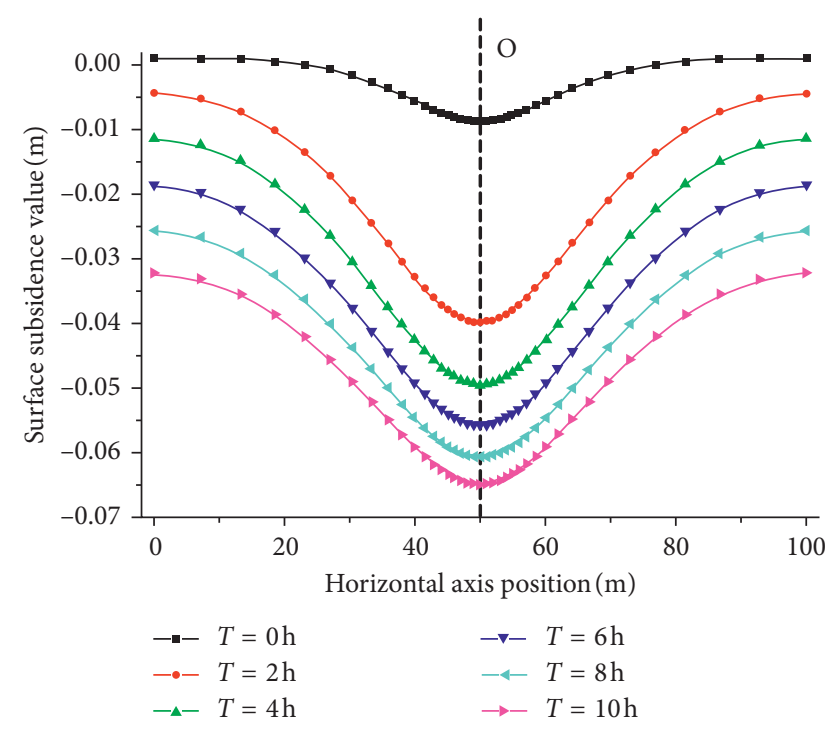

(d)

FIGURE 15: Surface subsidence diagram corresponding to water head difference $h$ at the top of the silty sand layer. (a) Surface subsidence at water head difference $h=4.5 \mathrm{~m}$. (b) Surface subsidence at water head difference $h=7.5 \mathrm{~m}$. (c) Surface subsidence at water head difference $h=10.5 \mathrm{~m}$. (d) Surface subsidence at water head difference $h=13.5 \mathrm{~m}$.

According to the fitted correlation between internal force-deformation of the segments and bolts and the different head differences $\Delta h$, the stresses and deformations are further developed under the condition that water is constantly gushing on the excavation surface with constantly changing head difference. With the increasing amount of water inrush (the head difference is constantly changing), the internal force-deformation of the segments and bolts exhibited a nonlinear increase trend. For C50 reinforced concrete segments, when the stress of the segment exceeded its tensile strength, the segment cracking caused more serious water flooding. For the high-strength bolt M30, the excessive stress caused the yield damage of the bolt by the tensile strength, which threatens the safety of the engineering structure. To ensure the safety of the forming structure of the subway shield tunnel, the design specification requires that the deformation of the subway segment is less than $15 \mathrm{~m}$, the stress of the segment cannot exceed $50 \mathrm{MPa}$ of the compressive strength of C50 concrete, and the tensile force of the segment cannot exceed $5 \mathrm{MPa}$ of the tensile strength of C50 concrete. The axial force and shear force of the M30 bolt cannot exceed $466 \mathrm{kN}$ and $215 \mathrm{kN}$, respectively [3]. Therefore, by fitting the internal force-deformation of the segments and bolts with the different head differences $\Delta h$, formulas (4)-(6) were used to calculate the limits. According to the calculation, under the condition of water inrush in the launching-arrival stage of the shield, the head difference on the excavation face should be less than $1.81 \mathrm{~m}$ to ensure the essential safety of the 


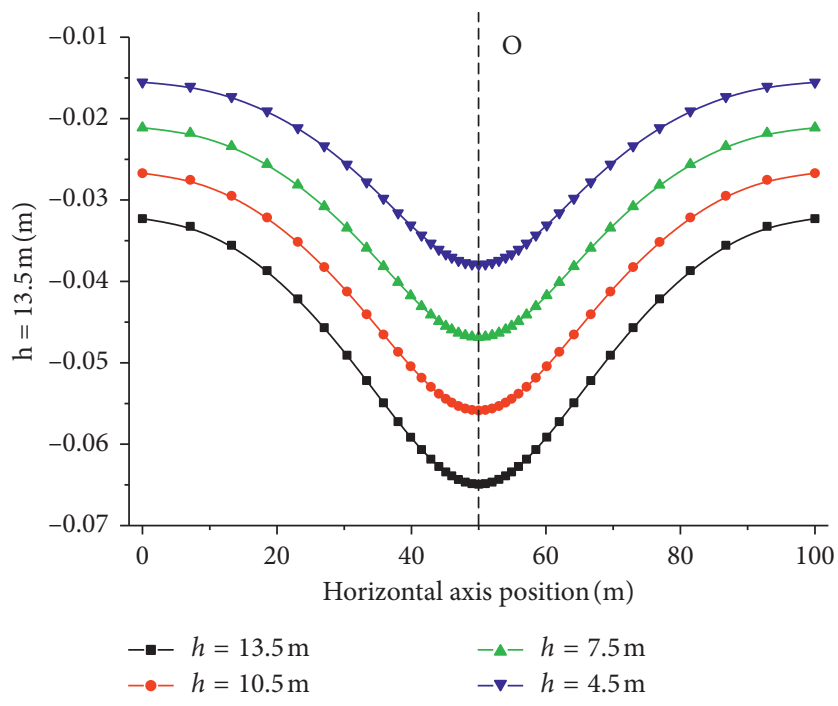

Figure 16: Comparison of final surface subsidence corresponding to different head differences.

shield tunnel segments and bolts. However, in the construction site at the launching-arrival stage of the shield construction, when the tunnel door has a sudden water inrush, the shield cutter enters the air medium after the tunnel portal is excavated; thus, maintaining the water head difference of the excavation surface at less than $1.81 \mathrm{~m}$ by effective control of the water discharge amount cannot be achieved. Therefore, the surrounding soil must be effectively strengthened before the shield machine excavates the tunnel portal to ensure the safety of the subway shield tunnel structure.

\section{Analysis of Emergency Control Measures for Soil Reinforcement in Shield Construction Launching-Arrival Stage}

According to the conclusion of Section 3.2, it is necessary to effectively reinforce the surrounding soil during the launching-arrival stage of the shield construction to ensure the safety of the forming structure of the subway shield tunnel under sudden inrush conditions. Therefore, in this section, numerical simulation analysis was conducted for the height $(H)$, length $(L)$, and width $(W)$ of the soil reinforced tunnel at the shield arrival stage (Figure 18). In addition, the effect of a large amount of water inrush in the front of the shield machine on the surface subsidence, and the internal force of the segment and the anchor bolt were investigated to formulate the emergency control measures for soil reinforcement at the launching-arrival stage of the shield construction.

In the construction site of the launching-arrival stage of the shield construction, when the flooding surface of the tunnel door suddenly overflows, it is impossible to effectively control the small water head difference of the excavation surface by effectively controlling the amount of water inflow from the site. Therefore, the water head difference was set in this section as $13.5 \mathrm{~m}$, which is the most unfavorable water inrush condition. The width of the soil reinforcement end was $W=40 \mathrm{~m}$ and $L=18 \mathrm{~m}$, and the reinforcement depth $H$ was set to $19 \mathrm{~m}, 15 \mathrm{~m}$, and $11 \mathrm{~m}$ to study their influences on the ground subsidence, the internal force of the segment, and anchor, respectively.

Figure 19 is a deformation nephogram of the segment with a depth of $19 \mathrm{~m}$. It can be seen from the figure that the maximum deformation value of the critical section $A-A^{\prime}$ segment was reduced from $42.7 \mathrm{~mm}$ to $22.9 \mathrm{~mm}$ under the condition of water inrush, compared with no reinforcement measures. The maximum deformation of the segment was also reduced by half. Therefore, if soil reinforcement measures are taken, even if there is a large amount of water inrush at the arrival stage of the shield, the soil reinforcement will not cause significant deformation of the segments.

Figure 20 is the maximum tensile stress and maximum compressive stress nephogram of the segment with the reinforcement depth $H=19 \mathrm{~m}$. It can be seen from the figure that even if the soil reinforcement measures were adopted in the tunnel portal, the segment will still have maximum tensile stress and maximum compressive stress under the condition of water inrush. However, compared with the measures without reinforcement, the risk of tensile failure of the segments is reduced. It is noteworthy that when the reinforcement depth was $H=19 \mathrm{~m}$, the maximum tensile stress of the segment was $4.9 \mathrm{MPa}$, which is less than the ultimate tensile strength of $5 \mathrm{MPa}$ of C50 concrete. Consequently, this measure resolves the issue caused by the inability to adjust the water head difference by controlling the flow of water inrush in the case of sudden water inrush on the excavation surface of the tunnel portal, as the shield cutter has entered the air medium after the tunnel portal is removed, which ensures the safety of the tunnel-forming structure.

Figure 21 is a schematic diagram of the surface subsidence tank of the $\mathrm{A}-\mathrm{A}^{\prime}$ section with the reinforcement depth of $H=19 \mathrm{~m}$. It can be seen from the figure that under 


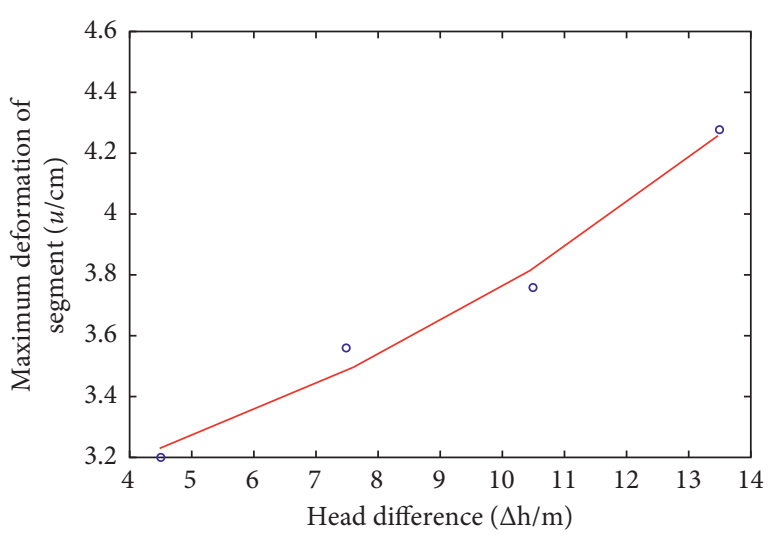

(a)

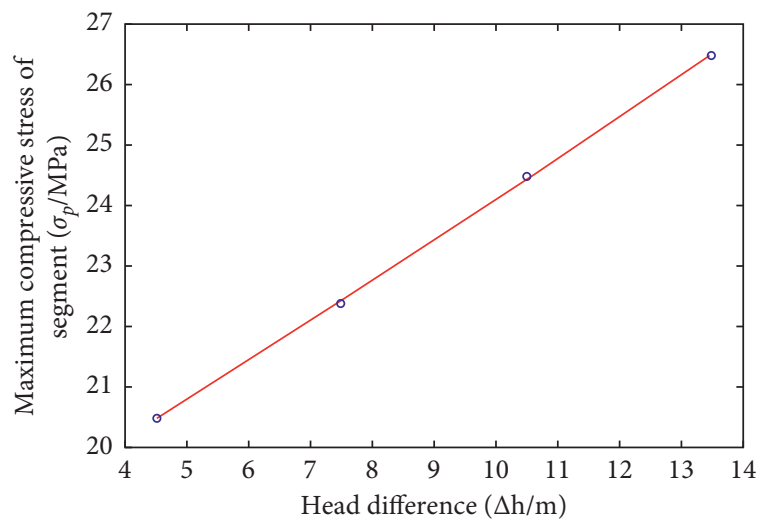

(c)

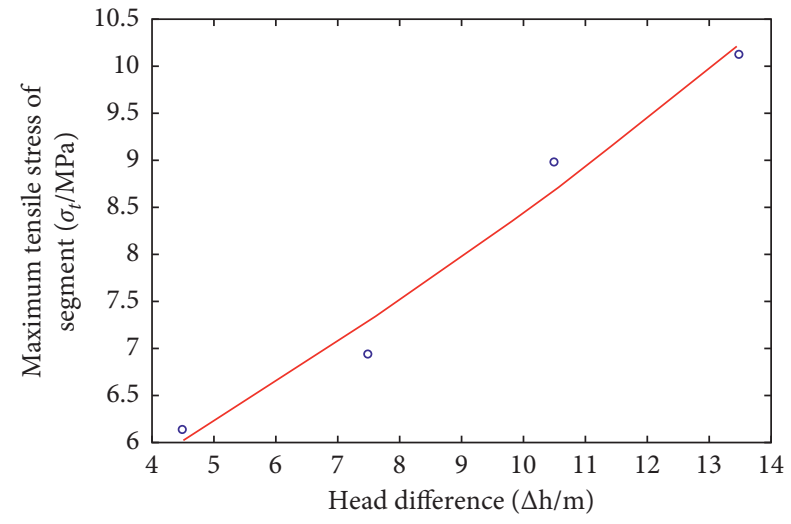

(b)

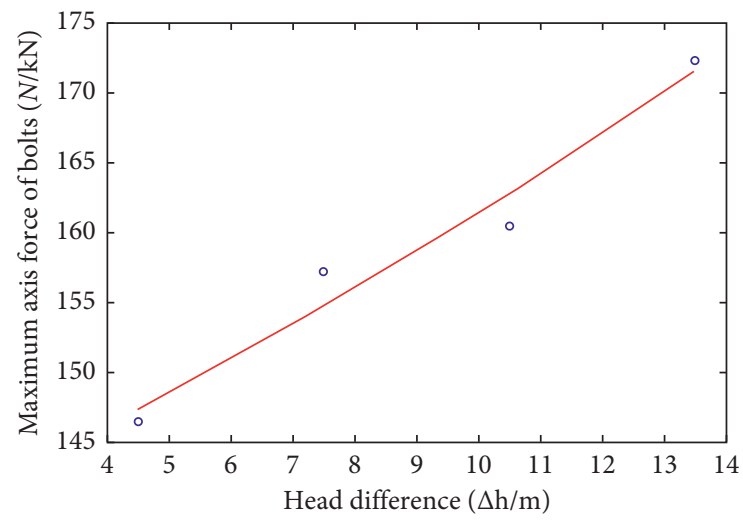

(d)

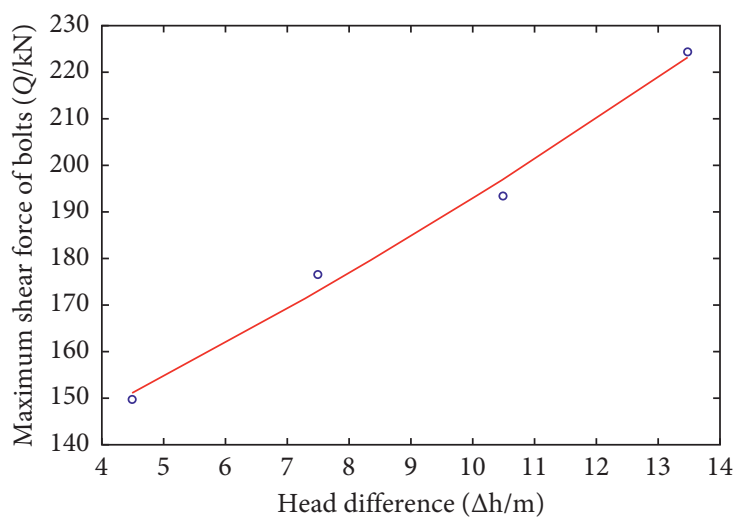

(e)

Figure 17: Maximum deformation value of the segment corresponding to the water head difference. (a) Maximum deformation value of the segment corresponding to the water head difference. (b) Maximum tensile stress of the segment corresponding to the water head difference. (c) Maximum compressive stress of the segment corresponding to the water head difference. (d) Maximum axial force of the bolt corresponding to the water head difference. (e) Maximum shear force of the bolt corresponding to the head difference.

the same water rushing condition, the maximum subsidence value of the ground surface was $29.3 \mathrm{~mm}$ at the intersection point $\mathrm{O}$ of the $\mathrm{A}-\mathrm{A}^{\prime}$ section and the tunnel axis section $\mathrm{B}-\mathrm{B}^{\prime}$, which is reduced by $35.6 \mathrm{~mm}$ compared with when no reinforcement measures are taken. Therefore, the reinforcement of the soil at the shield portal can not only reduce the internal force of the segment but also effectively control the surface subsidence.
The effects of soil reinforcement depths of $H=15 \mathrm{~m}$ and $H=11 \mathrm{~m}$ were analyzed separately. The results are shown in Figures 22 and 23. It can be seen from the figures that when the reinforcement depth was reduced, the subsidence value of the surface of the $\mathrm{A}-\mathrm{A}^{\prime}$ section increased accordingly. When the reinforcement depth was $11 \mathrm{~m}$, the maximum subsidence value at the intersection of the $\mathrm{A}-\mathrm{A}^{\prime}$ section and the tunnel axis section $\mathrm{B}-\mathrm{B}^{\prime}$ was $52.6 \mathrm{~mm}$. Compared with 


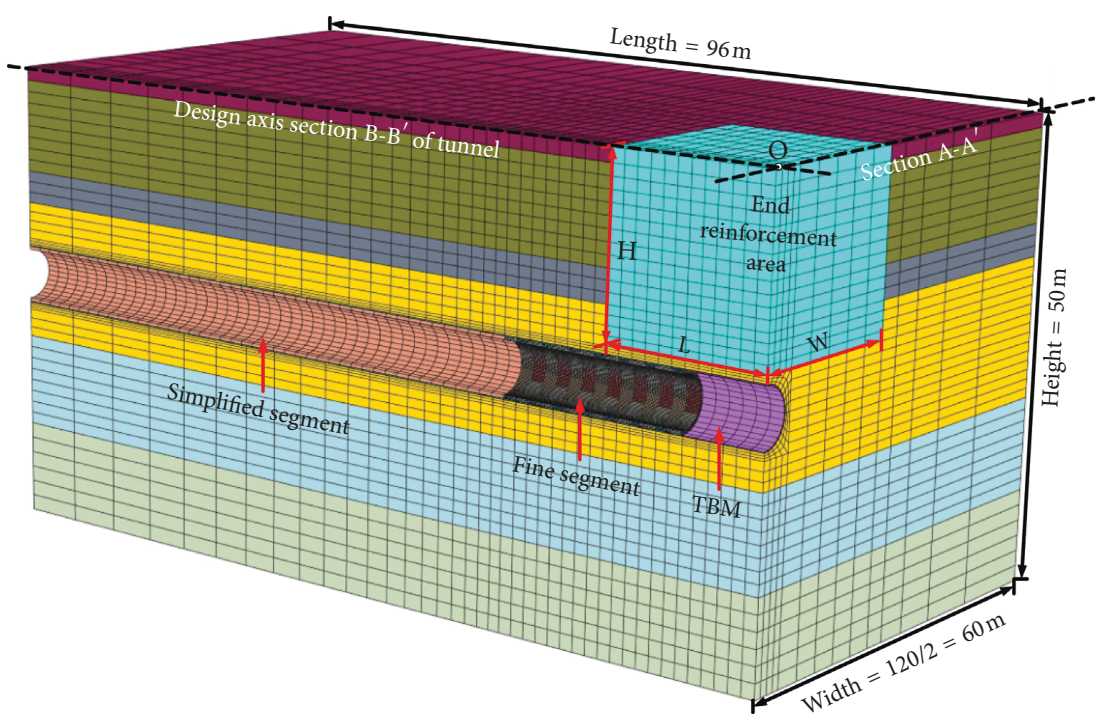

Figure 18: Schematic diagram of soil reinforcement at the shield arrival stage.

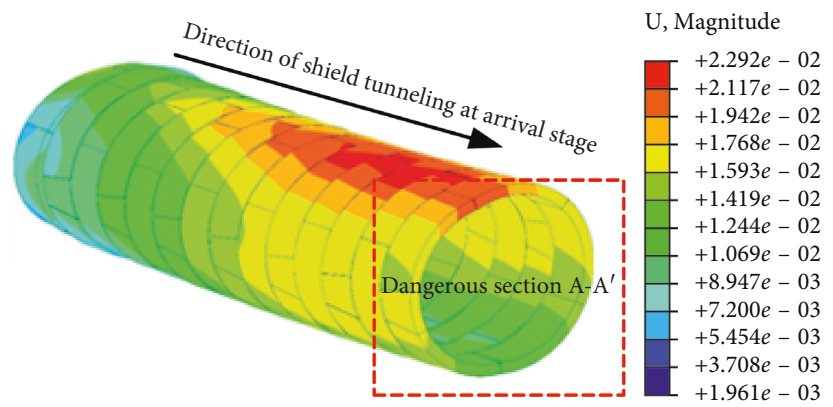

FIGURE 19: Segment deformation nephogram at the reinforcement depth of $H=19 \mathrm{~m}$.

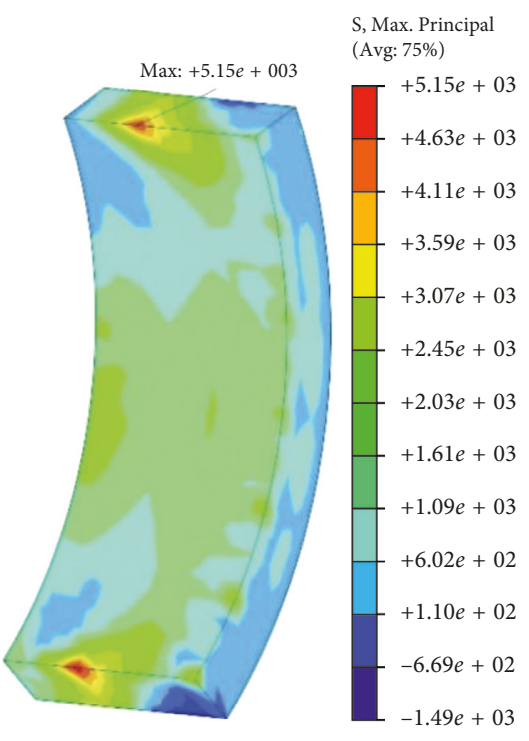

(a)

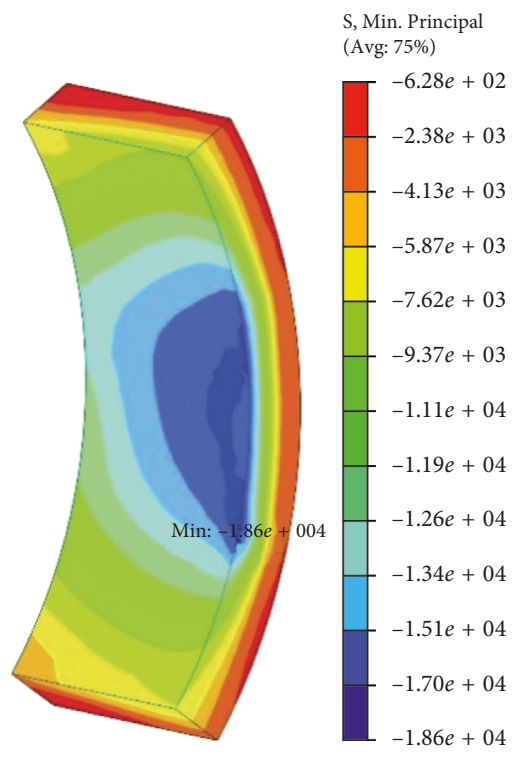

(b)

Figure 20: Maximum tensile and compressive stress of the segment with reinforcement depth of $H=19$ m. (a) Maximum tensile stress. (b) Maximum compressive stress. 


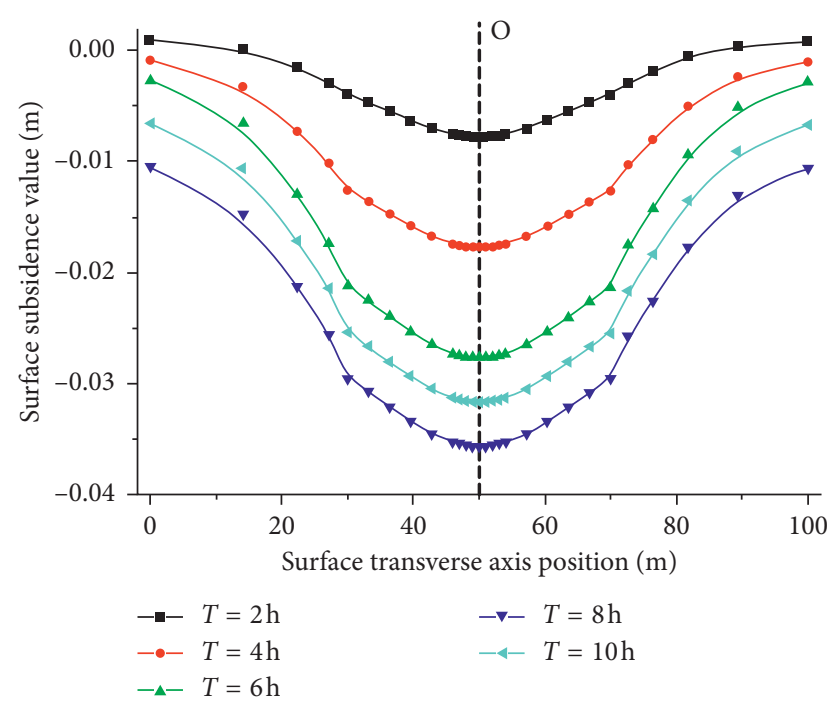

FIGURE 21: Schematic diagram of the surface settling tank with reinforcement depth of $H=19 \mathrm{~m}$.

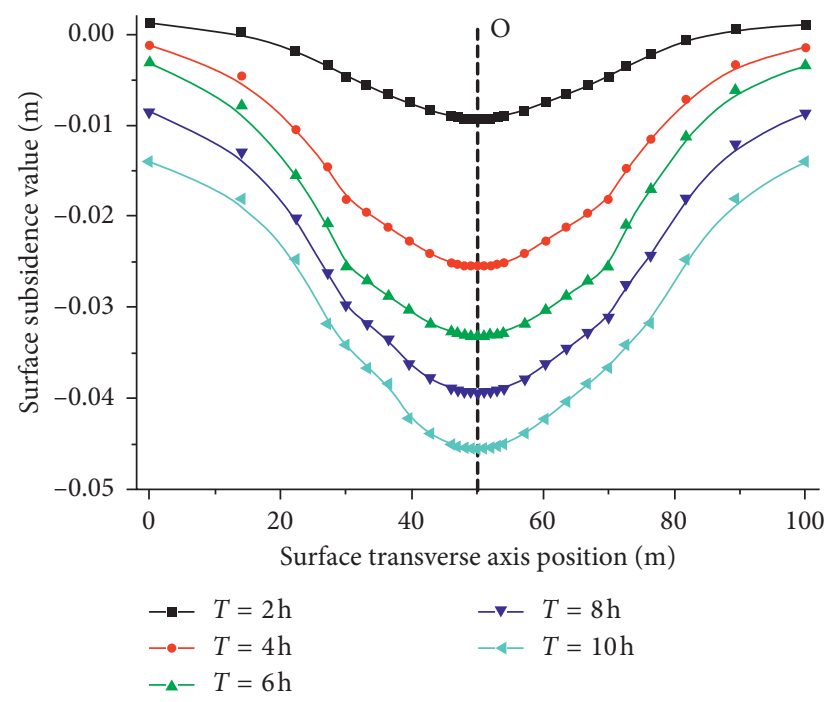

FIGURE 22: Surface subsidence tank at the reinforcement depth of $H=15 \mathrm{~m}$.

the unreinforced condition, the improvement effect is insignificant. Therefore, when the soil reinforcement is carried out at the arrival stage of the shield, sufficient reinforcement depth measures can effectively control the ground subsidence.

Figure 24 shows the trend of the internal force of the segment and bolt with the water inrush time. It can be seen from the figure that the depth of the soil reinforcement had a great control effect on the internal force of the tunnel. The increasing reinforcement depth played a control effect on both the deformation of the segment and the internal force of the bolt. For example, when the reinforcement depth was $19 \mathrm{~m}$, the maximum shear force value of the bolt at the intersection point of the $\mathrm{A}-\mathrm{A}^{\prime}$ section and the tunnel axis section B-B' was $123.5 \mathrm{~mm}$, which is very significant compared with the unreinforced maximum value of $224.5 \mathrm{~mm}$.

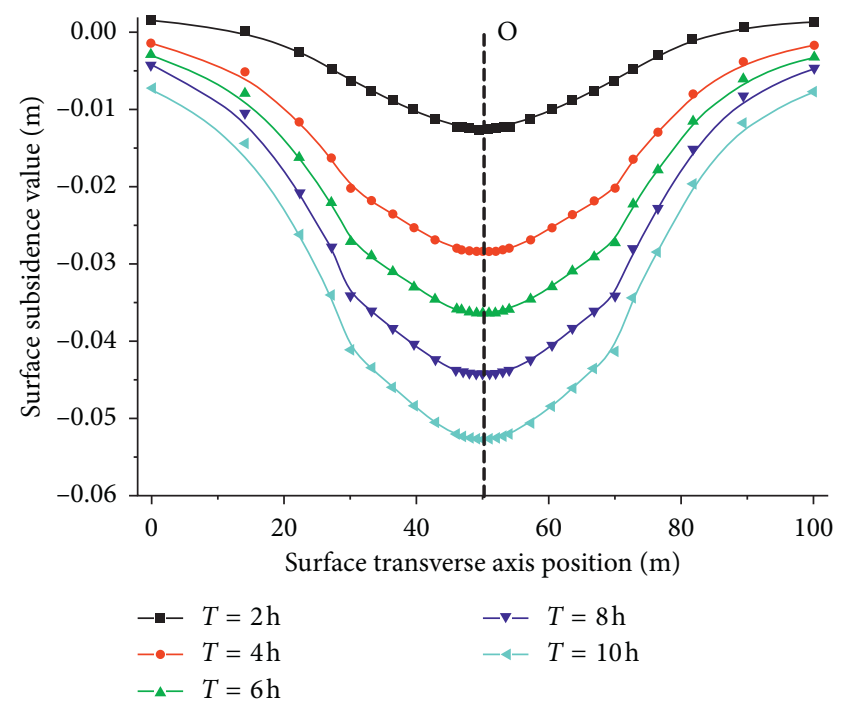

FIGURE 23: Surface subsidence tank at the reinforcement depth of $H=11 \mathrm{~m}$.

According to the simulation results of the water inrush conditions in the XW interval, the efficiency percentage weights of the emergency control measures for different reinforcement depths (Figure 25) are as follows: (1) Compared with unreinforced measure, the maximum deformations of the segments with the emergency reinforcement depths of $H=11 \mathrm{~m}, H=15 \mathrm{~m}$, and $H=19 \mathrm{~m}$ were decreased by $37.2 \%$, $44.2 \%$, and $46.5 \%$, respectively. (2) The maximum tensile stresses of the segment with the reinforcement depth of $H=11 \mathrm{~m}, H=15 \mathrm{~m}$, and $H=19 \mathrm{~m}$ were $19.8 \%, 41.6 \%$, and $51.5 \%$ lower than that without the reinforcement measures, respectively. (3) The maximum compressive stresses of the segment with the reinforcement depth of $H=11 \mathrm{~m}, H=15 \mathrm{~m}$, and $H=19 \mathrm{~m}$ were decreased by $10.9 \%, 18.5 \%$, and $27.9 \%$, respectively. (4) The maximum tensile stresses of bolts with the reinforcement depth of $H=11 \mathrm{~m}, H=15 \mathrm{~m}$, and $H=19 \mathrm{~m}$ were decreased by $16.5 \%, 20.7 \%$, and $29.3 \%$, respectively. (5) The maximum shear force of the bolts with the reinforcement depth of $H=11 \mathrm{~m}, H=15 \mathrm{~m}$, and $H=19 \mathrm{~m}$ was decreased by $25.3 \%, 36.1 \%$, and $44.9 \%$, respectively. (6) The ground subsidence with the reinforcement depth of $H=11 \mathrm{~m}, H=15 \mathrm{~m}$, and $H=19 \mathrm{~m}$ was reduced by $18.9 \%, 29.8 \%$, and $54.8 \%$, respectively.

Based on the above evaluation results of emergency control measures with different reinforcement depths, the comprehensive weights of the emergency control measures with $H=11 \mathrm{~m}, H=15 \mathrm{~m}$, and $H=19 \mathrm{~m}$ were $21.4 \%, 31.8 \%$, and $42.5 \%$, respectively. Considering the cost of reinforcement depth, we suggest that the reinforcement depth of the end soil should not be less than $15 \mathrm{~m}$ to prevent the damage of the shield tunnel caused by water inrush at the launching-arrival stage. In actual engineering, the risk factor of the shield at the launching-arrival stage is the highest. For safety concern, detailed simulation calculations should be performed on the soil reinforcement conditions at the launching-arrival stage, and appropriate reinforcement measures should be taken accordingly to 


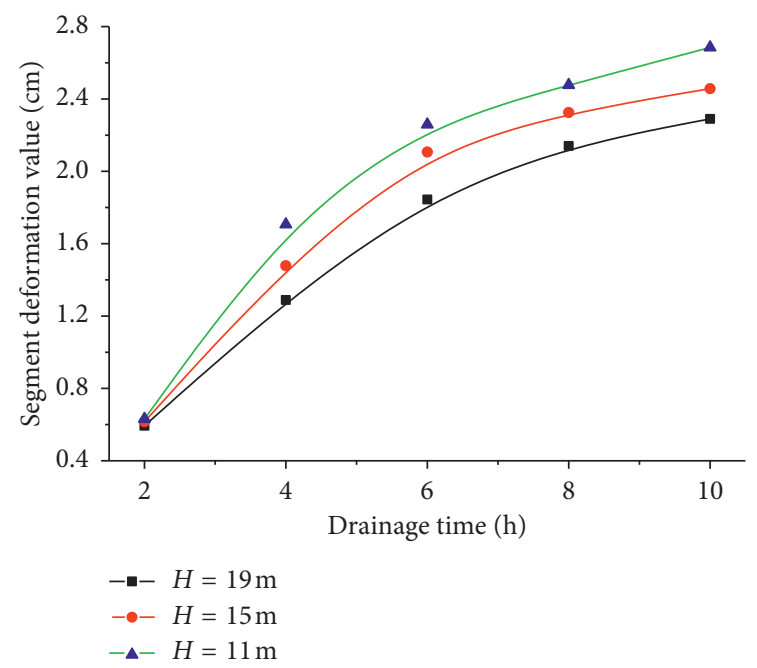

(a)

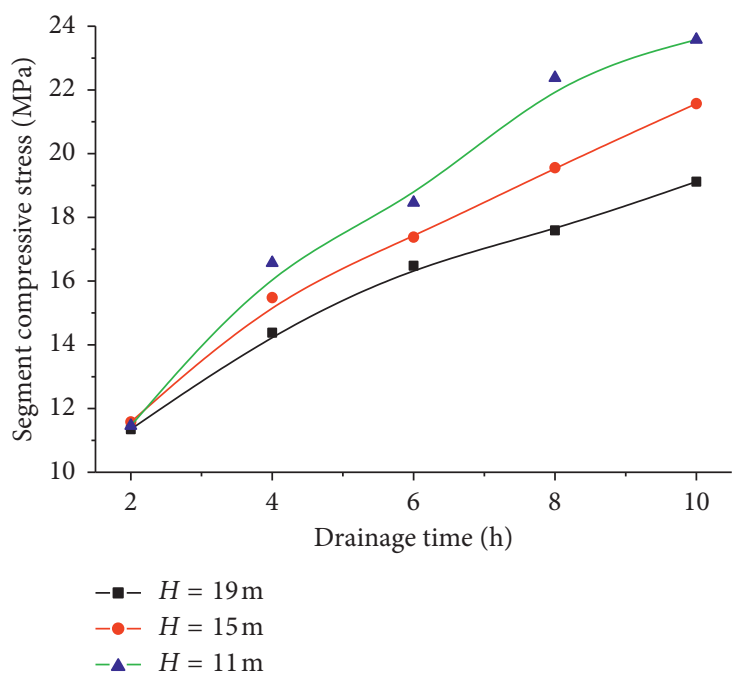

(c)

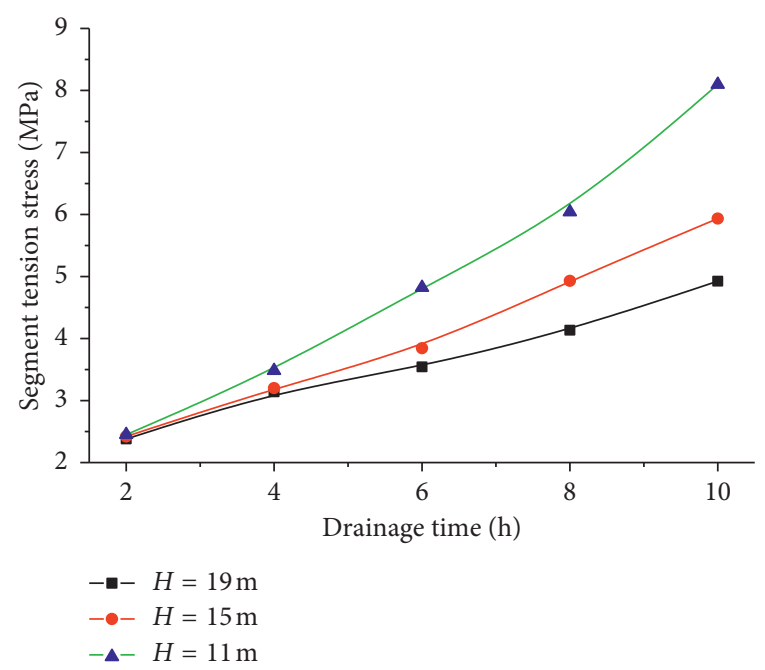

(b)

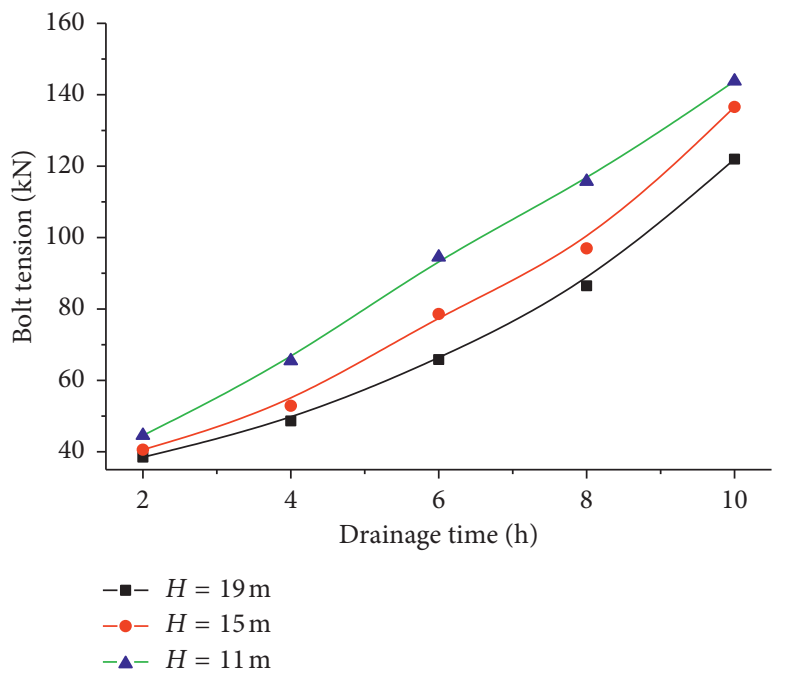

(d)

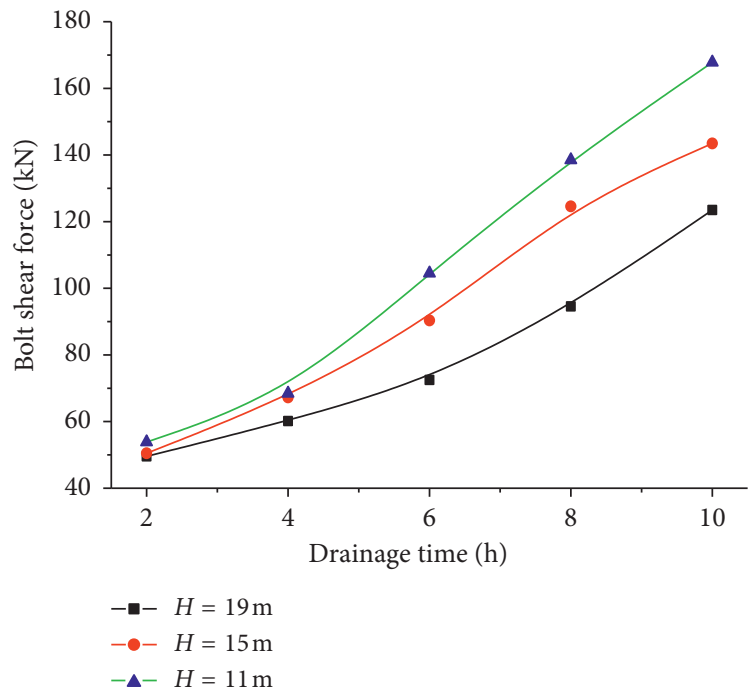

(e)

FIGURE 24: Internal force diagram of the segments and bolts corresponding to different reinforcement depths. (a) Maximum deformation value of the segment. (b) Maximum tensile stress of the segment. (c) Maximum compressive stress of the segment. (d) Maximum tensile force of bolts. (e) Maximum shear force of bolts. 


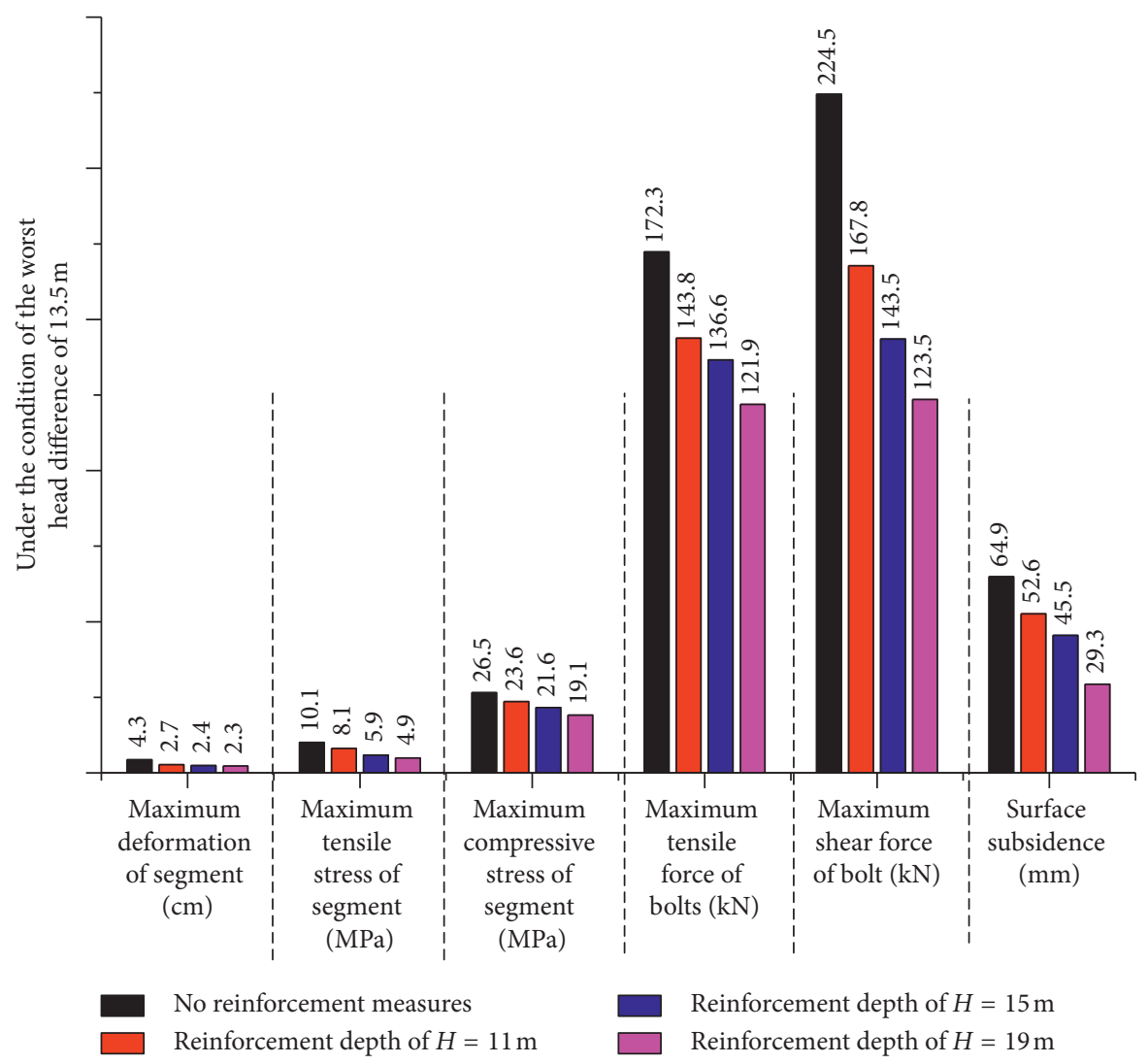

FIGURE 25: Efficiency percentage weight of emergency control measures with different reinforcement depths.

reduce water inrush and the adverse consequences of the accident.

\section{Conclusions}

Taking the Xiaodongmen-Wuchang Railway Station section as the research background, we established an equivalent refinement inrush model for the launching-arrival stage of shield tunnel construction, and studied the influences of changing water head difference on the excavation surface on the stress and deformation of the tunnel-forming structure (including the deformation and internal force of bolts and segments at the seam surface on the excavation face) under the water inrush conditions at the launching-arrival stage that has the highest risk in subway shield construction. This study might provide a reference for the tunnel engineering practice. The specific conclusions are as follows:

(1) The vertical convergence of the shield tunnel is mainly represented by the overall deformation of the existing tunnel-forming structure during the continuous change of the amount of inrush water on the excavation face. As the head difference of the excavation face changed constantly, the joint stress of the segment increased sharply. The local maximum tensile stress of the segment at the seam exceeded the ultimate tensile strength of the C50 concrete, resulting in partial cracking of the segment-forming structure. Moreover, the axial force of the bolt on the crown and waist was relatively significant. The shear force of the bolt at the critical section $\mathrm{A}-\mathrm{A}^{\prime}$ circumferential joint significantly increased, and the maximum shear force of the bolt exceeded the ultimate shear strength of $215 \mathrm{kN}$ with yield damage.

(2) When the head difference of the excavation surface was significant, the ground surface subsidence and the internal forces of the segments and bolts exhibited a nonlinear growth trend, which increases the risk of misalignment and extrusion cracking. Based on the water inrush condition in the XW interval, the surface subsidence and the variation trend of the internal forces of the segments and bolts were analyzed by simulating the soil reinforcement measures at different depths. On the basis of the results of the analysis, it was concluded that a depth of more than $15 \mathrm{~m}$ for the reinforced soil body is recommended in the launching-arrival stage of the shield to ensure safe construction during the launching-arrival stage of the shield.

\section{Data Availability}

The data used to support the findings of this study are available from the corresponding author upon request. 


\section{Conflicts of Interest}

The authors declare that they have no conflicts of interest.

\section{Acknowledgments}

The authors thank the workers, foremen, and safety coordinators of the main contractors for their participation. The authors also wish to thank engineer Peilun Tu for assistance in gathering field data.

\section{References}

[1] W. Liu, X. Wu, L. Zhang, J. Zheng, and J. Teng, "Global sensitivity analysis of tunnel-induced building movements by a precise metamodel," Journal of Computing in Civil Engineering, vol. 31, no. 5, Article ID 04017037, 2017.

[2] F. ye, N. Qin, X. Gao, X.-Y. Quan, X.-z. Qin, and B. Dai, "Shield equipment optimization and construction control technology in water-rich and sandy cobble stratum: a case study of the first yellow river metro tunnel undercrossing," Advances in Civil Engineering, vol. 2019, Article ID 8358013, 12 pages, 2019.

[3] T. Zhao, W. Liu, and Z. Ye, "Effects of water inrush from tunnel excavation face on the deformation and mechanical performance of shield tunnel segment joints," Advances in Civil Engineering, vol. 2017, Article ID 5913640, 18 pages, 2017.

[4] W.-C. Cheng, J. C. Ni, H.-W. Huang, and J. S. Shen, "The use of tunnelling parameters and spoil characteristics to assess soil types: a case study from alluvial deposits at a pipejacking project site," Bulletin of Engineering Geology and the Environment, vol. 78, no. 4, pp. 2933-2942, 2018.

[5] W. F. Lee and K. Ishihara, "Forensic diagnosis of a shield tunnel failure," Engineering Structures, vol. 32, no. 7, pp. 1830-1837, 2010.

[6] H. Li, "Foshan metro accident reporting major accidents of "2.7" permeable collapse of rail transit line 2," 2018, http:// news.e23.cn/redian/2018-07-31/2018073100176.html.

[7] H. Shi, M. Bai, and S. Xing, "Plastic zone analysis of deepburied, noncircular tunnel and application on the high-speed railway in the karst area," Mathematical Problems in Engineering, vol. 2017, Article ID 1853951, 10 pages, 2017.

[8] W. Yang, L. Jin, and X. Zhang, "Simulation test on mixed water and sand inrush disaster induced by mining under the thin bedrock," Journal of Loss Prevention in the Process Industries, vol. 57, pp. 1-6, 2019.

[9] S. Qin, Z. Ma, C. Jiang et al., "Application of magnetic resonance sounding to tunnels for advanced detection of waterrelated disasters: a case study in the Dadushan tunnel, Guizhou, China," Tunnelling and Underground Space Technology, vol. 84, pp. 364-372, 2019.

[10] W. Zhou and S. Liao, "The analysis and control of inrush and mud gushing in the broken rock tunnel under high water pressure," Procedia Engineering, vol. 165, pp. 259-264, 2016.

[11] Z. Ye and H. Liu, "Mechanism and countermeasure of segmental lining damage induced by large water inflow from excavation face in shield tunneling," International Journal of Geomechanics, vol. 18, no. 12, Article ID 04018163, 2018.

[12] J. Qiu, Y. Qin, J. Lai et al., "Structural response of the metro tunnel under local dynamic water environment in loess strata," Geofluids, vol. 2019, Article ID 8541959, 16 pages, 2019.
[13] X.-X. Liu, S.-L. Shen, Y.-S. Xu, and Z.-Y. Yin, "Analytical approach for time-dependent groundwater inflow into shield tunnel face in confined aquifer," International Journal for Numerical and Analytical Methods in Geomechanics, vol. 42, no. 4, pp. 655-673, 2018.

[14] H. K. Chen Kui and J. Shengjun, Shield Construction Technology, People's Communications Publishing House, Beijing, China, 2016.

[15] Z. Bing, Shield Construction of Metro, People's Communications Publishing House, Beijing, China, 2011.

[16] W. Liu, T. Zhao, Y. Zhang, Y. Chen, and W. Zhou, "Analysis of risk factors and countermeasures for metro shield construction," China Safety Science Journal, vol. 27, no. 10, pp. 130-136, 2017.

[17] W. Liu, T. Zhao, W. zhou, and J. Tang, "Safety risk factors of metro tunnel construction in China: an integrated study with EFA and SEM," Safety Science, vol. 105, pp. 98-113, 2018.

[18] Z. Li, L. Guo, and F. Cai, "Simulation study of soil triaxial compression based on drucker-prager yield criterion," Geotechnical Engineering Technique, vol. 23, no. 3, pp. 125-128, 2018.

[19] L. Resende and J. B. Martin, "Formulation of drucker-prager cap model," Journal of Engineering Mechanics, vol. 111, no. 7, pp. 855-881, 1985.

[20] W. Zhang, H. Zheng, F. Jiang, Z. Wang, and Y. Gao, "Stability analysis of soil slope based on a water-soil-coupled and parallelized smoothed particle hydrodynamics model," Computers and Geotechnics, vol. 108, pp. 212-225, 2019.

[21] W.-C. Cheng, J. C. Ni, J. S.-L. Shen, and H.-W. Huang, "Investigation into factors affecting jacking force: a case study," Proceedings of the Institution of Civil Engineers-Geotechnical Engineering, vol. 170, no. 4, pp. 322-334, 2017.

[22] W.-C. Cheng, J. C. Ni, A. Arulrajah, and H.-W. Huang, "A simple approach for characterising tunnel bore conditions based upon pipe-jacking data," Tunnelling and Underground Space Technology, vol. 71, pp. 494-504, 2018.

[23] W.-C. Cheng, L. Wang, Z.-F. Xue, J. C. Ni, M. M. Rahman, and A. Arulrajah, "Lubrication performance of pipejacking in alluvial deposits," Tunnelling and Underground Space Technology, vol. 91, Article ID 102991, 2019.

[24] Z. Ye, H. Liu, and L. Wen, "Analysis of influence of water inrush at shield tunneling face on ground surface settlement and internal stress of segment," Tuunel Construction, vol. 37, no. 10, pp. 1276-1286, 2017.

[25] Supervision NBoQaT GB 50299-1999, Code for Construction and Acceptance of Metro Engineering, China Planning Publishing House, Beijing, China, 2004. 


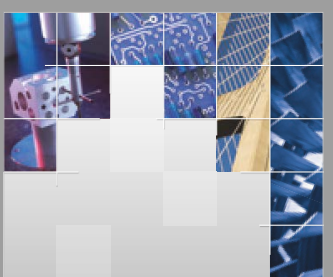

\section{Enfincering}
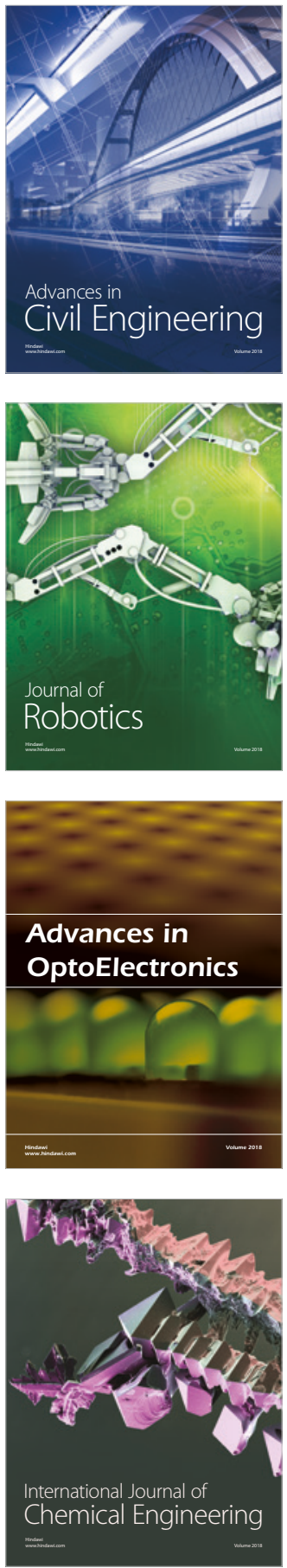

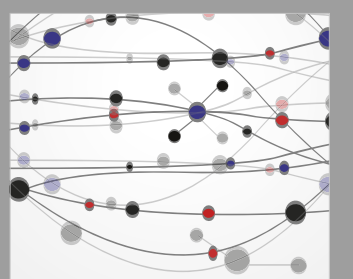

\section{Rotating \\ Machinery}

The Scientific World Journal

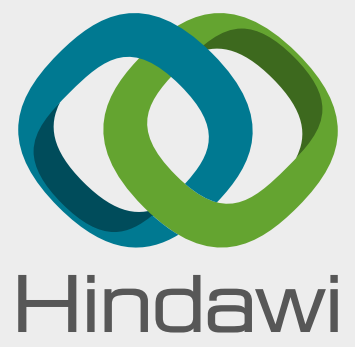

Submit your manuscripts at

www.hindawi.com
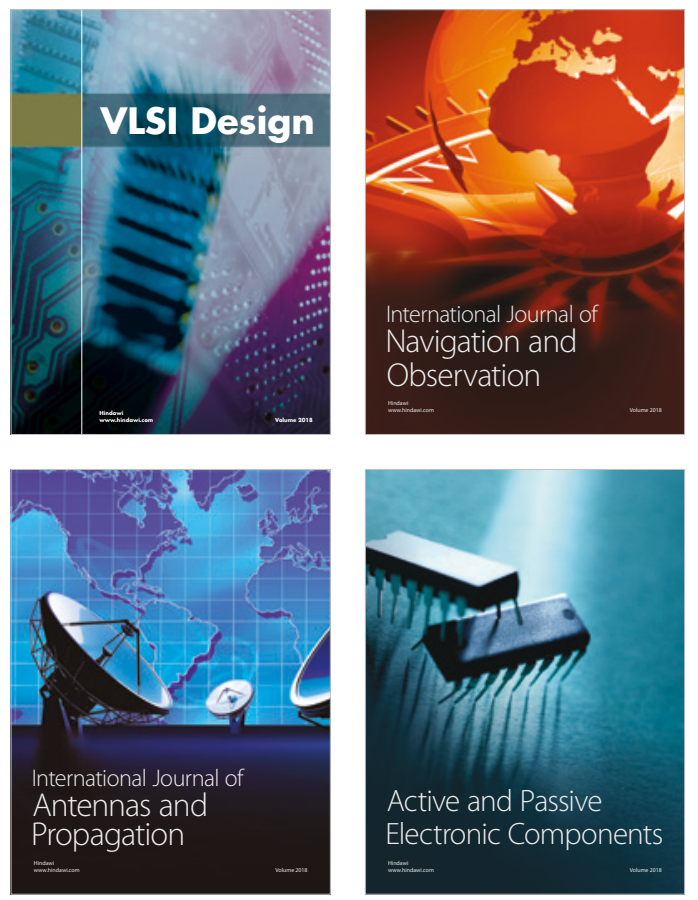
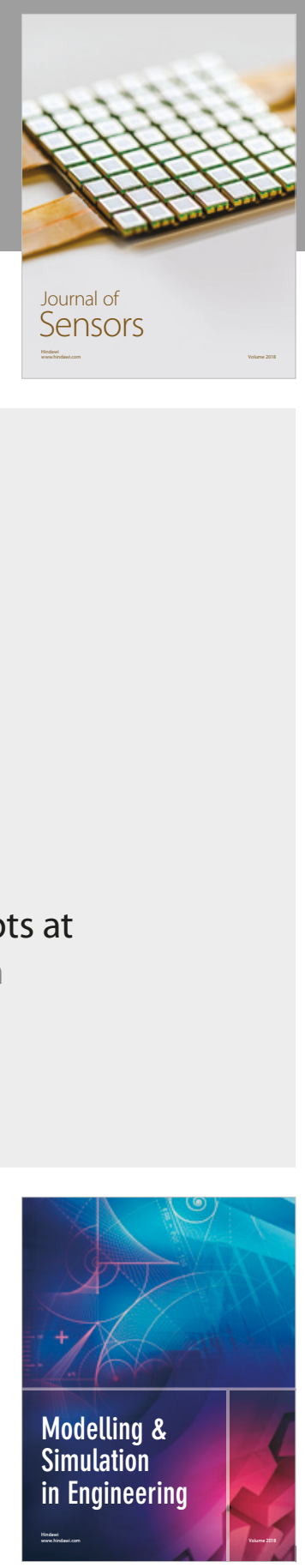

\section{Advances \\ Multimedia}
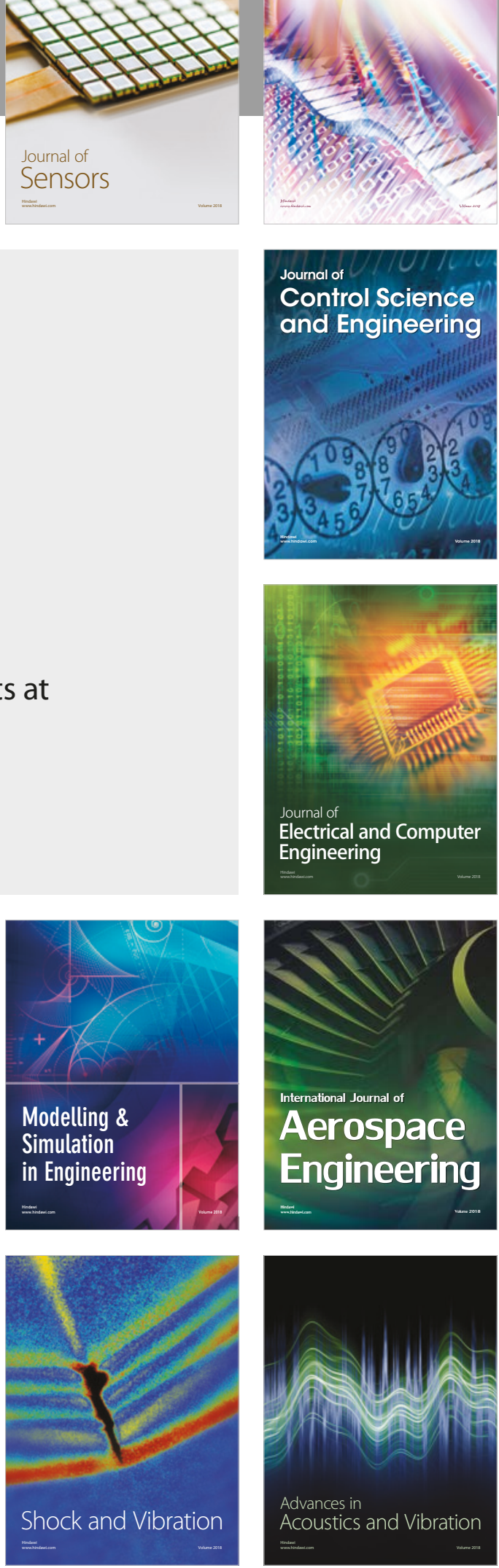